\title{
Avifauna no Refúgio de Vida Silvestre Mata do Buraquinho, João Pessoa, Paraíba, Brasil, com notas naturalísticas sobre as espécies ameaçadas
}

\section{Antônio Cláudio C. de Almeida}

Prefeitura Municipal de João Pessoa. Secretaria Municipal de Meio Ambiente. Centro Administrativo Municipal. Rua Diógenes Chianca, 1777. Água Fria. João Pessoa-PB, Brasil (CEP 58053-900). E-mail: acca40@gmail.com.

Resumo. A conservação da biodiversidade nas atuais condições de pressões antrópicas, pressupõe a implantação de unidades de conservação. No Município de João Pessoa (PB), a Mata do Buraquinho, consiste em unidade de conservação de proteção integral - refúgio de vida silvestre. Assim, o objetivo desta pesquisa foi elaborar um check list da avifauna desta unidade de conservação, no período de março de 2017 a fevereiro de 2018. No inventário, aplicou-se o método das Listas de Mackinnon, onde foram obtidas 84 listas de 10 espécies. Foram registradas 113 espécies de aves, representadas por 34 famílias, sendo as de maior riqueza de espécies Tyrannidae e Thraupidae, com 30 espécies (27\%), enquanto 28 espécies (25\%) são consideradas indicadoras de alterações ambientais. Foram registrados oito táxons endêmicos do Brasil e do Bioma Mata Atlântica, no Centro de Endemismo Pernambuco, Picumnus pernambucensis, Touit surdus, Xiphorhynchus atlanticus, Xenops minutus alagoanus, Iodopleura pipra leucopygia, Hemitriccus griseipectus naumburgae, Ramphocelus bresilius e Leptodon forbesi. Seis táxons estão ameaçados de extinção, Leptodon forbesi (EN), Touit surdus (VU), Xenops minutus alagoanus (VU), Iodopleura pipra leucopygia (CR) e Hemitriccus griseipectus naumburgae (VU). Os impactos ambientais negativos constatados para a avifauna são a coleta e o corte seletivo de plantas, a poluição hídrica, a pesca, a caça, as queimadas, a poluição sonora e a (re)introdução de espécies da fauna nativa. A observação de aves e a educação ambiental envolvendo as comunidades em torno da mata são instrumentos de inclusão social na conservação desta área protegida. Pode-se concluir que esta unidade de conservação consiste em um remanescente de extrema relevância ecológica para a conservação da avifauna da Mata Atlântica.

Palavras-chave: Aves; Nordeste; Brasil; Conservação da natureza; Fragmentação florestal; Perda de habitat; Áreas protegidas; Riqueza de espécies; Aves ameaçadas.

Abstract. The avifauna in the Mata do Buraquinho Wildlife Refuge, João Pessoa, Paraíba, Brazil, with naturalistic notes on threatened species. The conservation of biodiversity in the
Recebido

$21 / 09 / 2020$

Aceito

$15 / 01 / 2021$

Disponível on line

$24 / 01 / 2021$

Publicado

$30 / 04 / 2021$

Acesso aberto

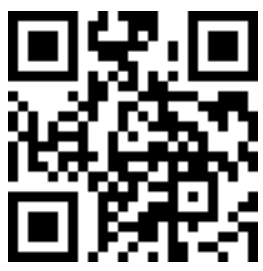

ORCID

(1) 0000-0003-2215-2323 Antônio Cláudio C. de Almeida 
current conditions of anthropic pressure, presupposes the establishment of conservation units. In the Municipality of João Pessoa (PB), Mata do Buraquinho, consists of a fully protected conservation unit - wildlife refuge. Thus, the objective of this research was to prepare a check list of the avifauna of this conservation unit, from March 2017 to February 2018. In the inventory, the Mackinnon Lists Method was applied, where 84 lists of 10 species were obtained. Were registered 113 bird species, represented by 34 families, with the highest species richness Tyrannidae and Thraupidae, with 30 species (27\%), while 28 species (25\%) are considered indicators of environmental changes. Eight taxa endemic to Brazil and the Atlantic Forest Biome were registered at the Pernambuco Endemism Center, Picumnus pernambucensis, Touit surdus, Xiphorhynchus atlanticus, Xenops minutus alagoanus, Iodopleura pipraleucopygia, Hemitriccus griseipectus naumburgae, Ramphocelus bresilius and Leptodon forbesi. Six taxa are threatened with extinction, Leptodon forbesi (EN), Touit surdus (VU), Xenops minutus alagoanus (VU), Iodopleura pipra leucopygia (CR) and Hemitriccus griseipectus naumburgae (VU). The negative environmental impacts observed for avifauna are the collection and selective cutting of plants, water pollution, fishing, hunting, burning, noise pollution, and the (re)introduction of species of native fauna. Bird watching and environmental education involving communities around the forest are instruments of social inclusion in the conservation of this protected area. It can be concluded that this conservation unit consists of a remnant of extreme ecological relevance for the conservation of Atlantic Forest avifauna.

Keywords: Birds; Northeast; Brazil; Forest fragmentation; Habitat loss; Nature conservation; Protected areas; Species richness; Endangered birds.

\section{Introdução}

A conservação da biodiversidade notoriamente nas atuais condições de pressões antrópicas nos biomas brasileiros, pressupõe a criação e manutenção de Unidades de Conservação (UC), nos termos da Lei no 9.985/2000, que instituiu o Sistema Nacional de Unidades de Conservação (SNUC) (Brasil, 2000). Sendo assim, o estabelecimento de áreas naturais sob proteção legal é uma das ferramentas fundamentais para a conservação, garantindo a preservação dos processos que mantêm e geram a biodiversidade (Simon e Gouveia, 2011).

A Mata do Buraquinho é um dos remanescentes de Mata Atlântica que sofreu forte pressão antrópica na Paraíba, nas últimas décadas do século XX. Com uma área equivalente a 512,93 hectares, consistindo em um dos remanescentes mais significativos da Mata Atlântica no Estado e prioritário para a conservação no Município de João Pessoa, o qual se destaca pela sua extensão e relevância ecológica (Andrade-Lima e Rocha, 1971; Barbosa, 1996; PMJP, 2012; Albuquerque e Duré, 2013; SUDEMA, 2014). Com base nas suas características peculiares, a Mata do Buraquinho foi considerada área prioritária de extrema importância biológica (Brasil, 2007a).

A Mata do Buraquinho, resquício de Mata Atlântica, do ponto de vista legal, é um dos ecossistemas mais protegidos do Estado da Paraíba. Além da proteção concedida à 
área pela Lei no 11.428/2006, a Lei da Mata Atlântica (Brasil, 2006), por força do Decreto no 98.181/1989 (Brasil, 1989) todo o seu perímetro foi declarado de preservação permanente. Através do Decreto no $21.264 / 2000$, parte de sua área foi transformada em jardim botânico (Paraíba, 2000), em 2004, o Conselho Nacional da Reserva da Biosfera da Mata Atlântica, em nome da Organização das Nações Unidas para a Educação, a Ciência e a Cultura (UNESCO), autorga ao Jardim Botânico Benjamim Maranhão o título de Posto Avançado da Reserva da Biosfera da Mata Atlântica (SUDEMA, 2014). Por fim, em julho de 2014, a Mata do Buraquinho foi transformada em unidade de conservação, através do Decreto no 35.195/2014, na categoria de proteção integral, como Refúgio de Vida Silvestre (RVS) (Paraíba, 2014), o qual, de acordo com a lei do Sistema Nacional de Unidades de Conservação (SNUC), tem como objetivo proteger ambientes naturais onde se asseguram condições para a existência ou reprodução de espécies ou comunidades da flora local e da fauna residente ou migratória (Brasil, 2000, art. 13).

A biodiversidade desta unidade de conservação (UC) possui alta prioridade para realização de pesquisas, no sentido de subsidiar a elaboração do seu plano de manejo. Dentre os grupos da fauna, as aves estão entre o grupo sem informações disponíveis na literatura para a área, conforme apontado pelos estudos utilizados para subsidiar a criação da referida unidade de conservação (SUDEMA, 2014). Entretanto, foram realizados alguns estudos faunísticos na área, tais como da herpetofauna (Santana et al., 2008; Rodrigues et al., 2013), com descrição de uma espécie nova de serpente (Pires et al., 2014), estudos dos aracnídeos (Dias et al., 2006a; Dias et al., 2006b) e dos lepidópteros (Kesselring e Ebert, 1979).

Com relação às aves, a RVS Mata do Buraquinho não apresenta informações disponíveis na literatura com estudos detalhados. Exceto um estudo voltado para o ecoturismo de observação de aves, realizado por Mélo (2015), no qual foram listadas 20 espécies, nas 12 trilhas usadas para visitação pública no Jardim Botânico Benjamim Maranhão, e o estudo etnoecológico de Alves et al. (2017), com moradores no entorno da Mata do Buraquinho, o qual registrou a presença de 47 espécies de aves e investigou a percepção e uso da biodiversidade pelas comunidades humanas no seu entorno, numa perspectiva etnobiológica, na qual ficou demonstrado o reconhecimento pela população investigada das funções ecológicas da floresta para a qualidade de vida local e os impactos ambientais negativos sobre a biodiversidade da mesma.

Nos últimos anos, os indicadores ecológicos têm sido utilizados para detectar mudanças ambientais e atualmente são usados para avaliar as condições ambientais (Niemi e McDonald, 2004). Sendo assim, o grupo zoológico Aves é um dos mais conspícuos e bem representados nos diferentes ecossistemas, tanto em número de espécies, abundância e de maior biomassa em florestas neotropicais (Terborgh et al., 1990). Atuam como polinizadores e dispersores chave de diversos grupos de angiospermas (Levey et al., 2005). Ainda, ocupam uma representativa diversidade de hábitats, o que lhes conferem uma importância significativa como indicadores biológicos da qualidade ambiental, inclusive aqueles resultantes de alterações de origem antrópica (Oren, 2001).

O Brasil possui 1.919 espécies de aves, cerca de 23,14\% de todas as espécies de vertebrados conhecidos para o país (Piacentini et al., 2015). Dessas, 234 espécies estão ameaçadas de extinção (Brasil, 2014b), sendo que quatro são endêmicas da Mata Atlântica do Centro de Endemismo Pernambuco (CEP) (Brasil, 2005; Roda et al., 2011), já foram dadas como extintas na natureza (Brasil, 2016). Para a RVS Mata do Buraquinho existe registro de uma das espécies em perigo de extinção (Brasil, 2016) no nordeste brasileiro. O gavião-gato-do-nordeste Leptodon forbesi (Swann, 1922) é uma das aves de rapina mais ameaçadas do mundo, com registros pontuais na região nordeste do Brasil (Pereira et al., 2006; Pereira et al., 2014; Pereira et al., 2019).

Para o Município de João Pessoa são conhecidas 182 espécies de aves, com oito ameaçadas de extinção (Falcão et al., 1992; PMJP, 2012; Brasil, 2014b; Brasil, 2016), porém são pouco conhecidas as espécies que compõem a comunidade de aves da RVS Mata do Buraquinho, exceto por observações aleatórias realizadas entre 1989 até 2012, quando 
foram compiladas para compor o Plano Municipal de Conservação e Recuperação da Mata Atlântica (PMJP, 2012).

Assim, o objetivo desta pesquisa foi elaborar um check list da avifauna do Refúgio de Vida Silvestre (RVS) Mata do Buraquinho, em João Pessoa, Estado da Paraíba, a fim de incrementar o conhecimento sobre a biodiversidade desta unidade de conservação, para fins de elaboração do seu plano de manejo e de outros estudos científicos.

\section{Material e métodos}

\section{Área de estudo}

O Refúgio de Vida Silvestre Mata do Buraquinho está localizado na porção sudoeste do Município de João Pessoa, no Estado da Paraíba, Brasil, ocupando área de 512,93 ha, com perímetro de 10.162,83 m (Decreto no 36.955/2016), no litoral do Estado da Paraíba (Paraíba, 2016). Compreende um remanescente de Florestal Estacional Semidecidual (Brasil, 1981) ou classificada como Floresta dos Tabuleiros (Thomas, 2008). A vegetação é recortada, na sua parte central pelo Rio Jaguaribe e faz limites com sete bairros da zona urbana do Município de João Pessoa (Castelo Branco, Jardim São Paulo, Água Fria, Cristo Redentor, Varjão, Jaguaribe e Torre) (Figuras 1 e 2).

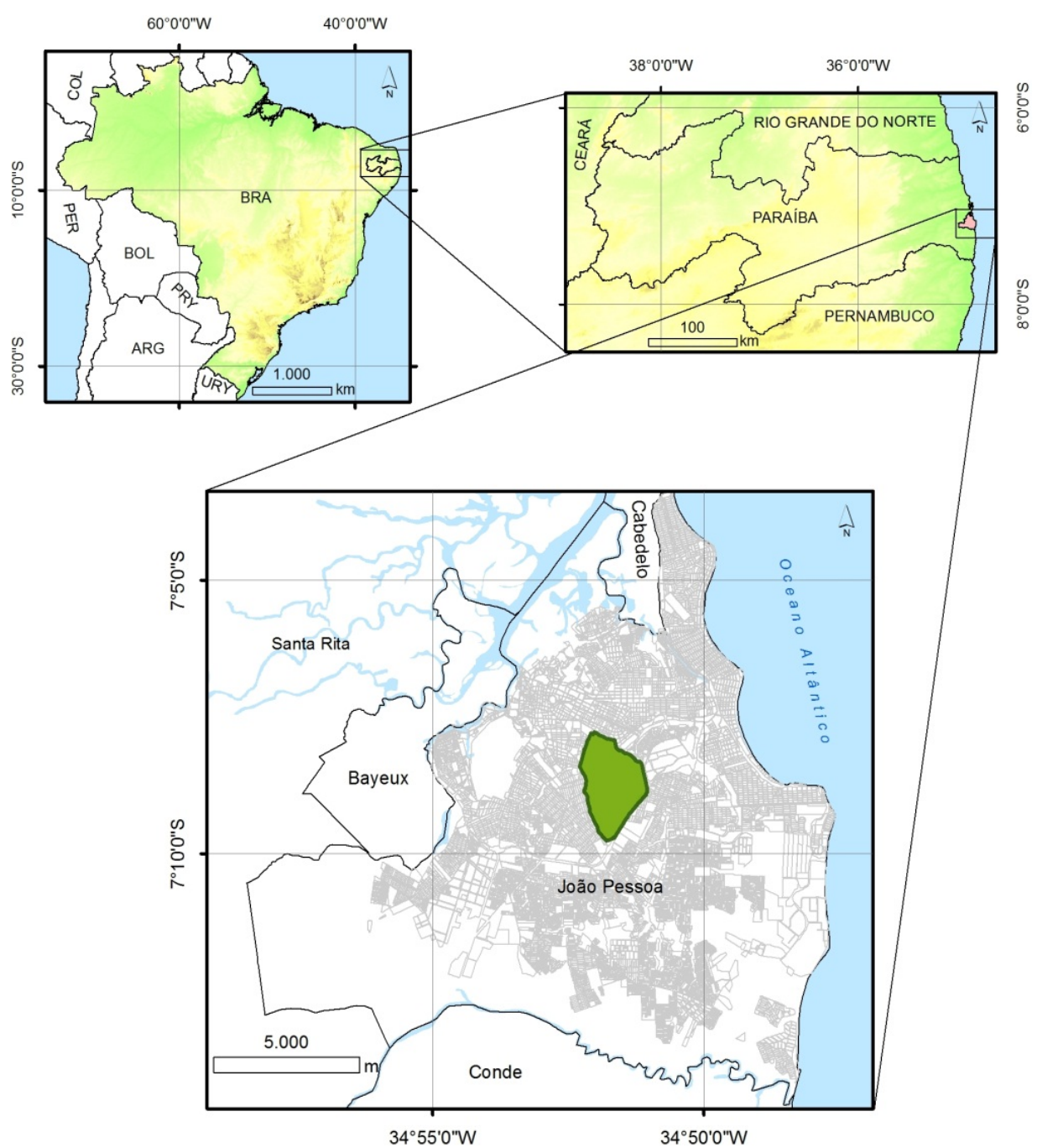

Figura 1. Localização do Refúgio de Vida Silvestre Mata do Buraquinho, no Município de João Pessoa-PB, no Nordeste do Brasil. 


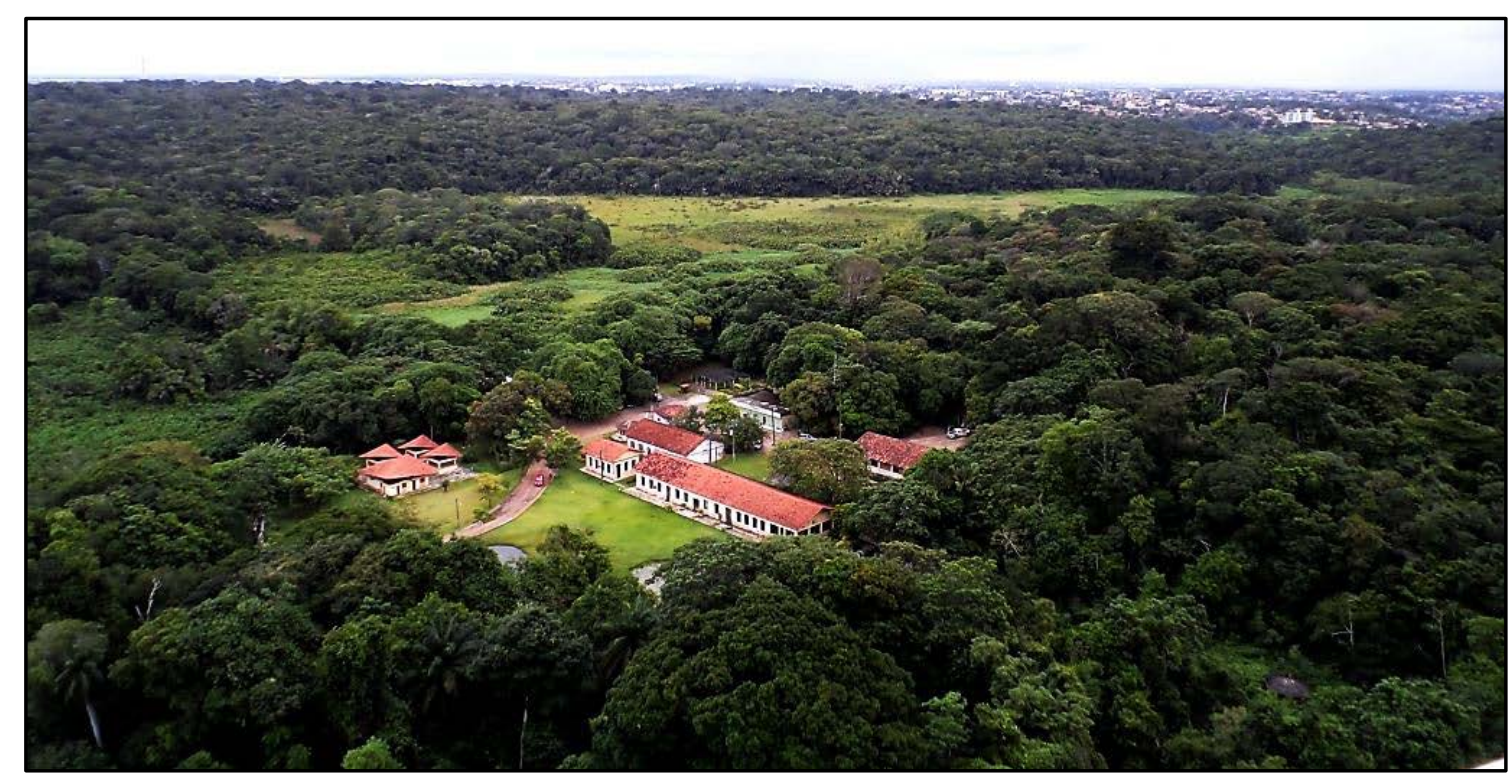

Figura 2. Vista aérea do Refúgio de Vida Silvestre Mata do Buraquinho, João Pessoa-PB, mostrando a sede do Jardim Botânico. Foto: Edvaldo E. Nunes, junho de 2016.

\section{Coleta dos dados}

O estudo da composição das aves do remanescente florestal da RVS Mata do Buraquinho foi realizado no período de março de 2017 a fevereiro de 2018, ao longo das 12 trilhas já estabelecidas na unidade de conservação, adaptadas a partir da descrição dada por Gadelha Neto (2008) (Tabela 1), com um total de 7.285 m de extensão.

Tabela 1. Trilhas na RVS Mata do Buraquinho. As trilhas base estão em negrito.

\begin{tabular}{l|c}
\hline Trilha & Extensão (m) \\
\hline Rio (River) (TR) & 294 \\
\hline Preguiça (Sloth) (TP) & $\mathbf{1 . 5 3 3}$ \\
\hline Buriti (Buriti palm) (TBu) & 162 \\
\hline Ilha (Island) (TI) & $\mathbf{1 . 5 2 7}$ \\
\hline Bambuzal (Bamboo) (TBa) & 340 \\
\hline Jiboia (Boa) (TJ) & 728 \\
\hline Vigia (Watchman) (TV) & 318 \\
\hline Macaco (Monkey) (TM) & 255 \\
\hline Abraço (Embrace) (TA) & 161 \\
\hline Munguba (Munguba) (TMu) & 595 \\
\hline Dendezeiro (Oil palm) (TD) & $\mathbf{1 . 0 3 7}$ \\
\hline Nascente (Water spring) (TN) & \\
\hline
\end{tabular}

Como critério utilizado para aumentar a cobertura espacial para os levantamentos, bem como aumentar o esforço de campo, as trilhas da Nascente (TN), do Bambuzal (TBa) e do Buriti (TBu) foram consideradas trilhas base (Figura 3), por serem as de maior extensão, e as demais de complementares. Os levantamentos foram realizados no período de 11 meses, sempre uma trilha base, uma trilha complementar e outro levantamento em dois trechos, selecionados a priori, a sudeste (Pse; coordenadas UTM 295305.5435; 9209285.2593; zona 25M) e oeste (Po; coordenadas UTM 293892.1169; 9209967.8803; zona $25 \mathrm{M}$ ) da unidade de conservação, áreas mais centrais da unidade de conservação e 
de acesso restrito (Figura 4). Desta maneira, foram realizadas observações nos diferentes habitat da unidade de conservação, os quais incluem a (i) floresta em estágio avançado de regeneração/primária (vegetação densa e dossel fechado), bem como nas (ii) bordas da área a sudeste (Pse), onde a vegetação encontra-se mais rarefeita com alterações mais acentuadas, (iii) outra área a oeste (Po), onde se encontra um riacho isolado e com a mata ciliar contínua e relativamente bem conservada e (iv) na mata ciliar em ambas as margens do Rio Jaguaribe.
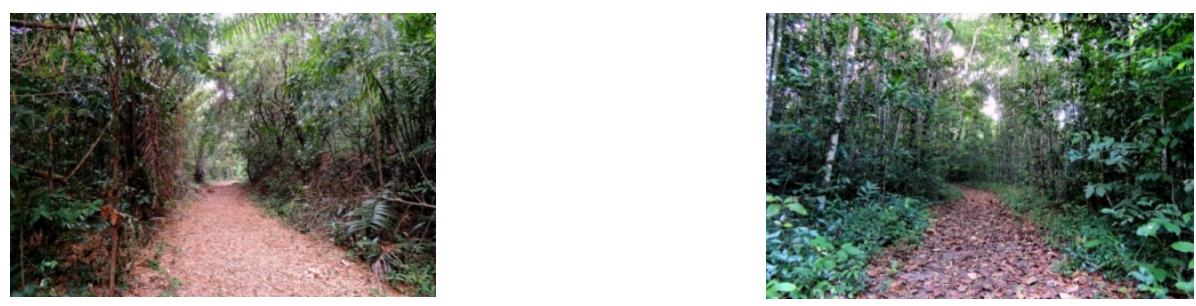

a

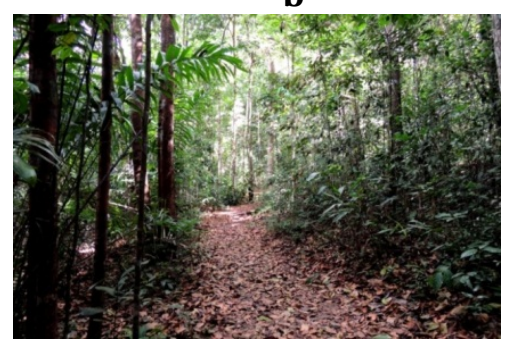

C

Figura 3. Trilhas do Bambuzal (a), do Buriti (b), e da Nascente (c), na RVS Mata do Buraquinho. Fotos: Dezembro, 2016.

Foram realizadas $121 \mathrm{~h}$ e 27 min de levantamento, entre $4 \mathrm{~h}$ e $30 \min$ e $12 \mathrm{~h}$ e 30 min, com uma média de 1 h, 26 min e 41 s. Foram realizados levantamentos no turno da tarde, incluindo a noite, entre $13 \mathrm{~h}$ e $18 \mathrm{~h}$ (total de $7 \mathrm{~h}$ e $41 \mathrm{~min}$ ). Foram percorridas uma extensão de $30.789 \mathrm{~m}$, com base nas trilhas marcadas.

As pesquisas de campo foram realizadas ao longo de 11 meses (março de 2017 a fevereiro de 2018), incluindo a estação chuvosa (março a junho) e a seca (setembro a dezembro) no município (Furrier, 2007).

A avifauna foi inventariada através da metodologia de observação direta (visual), aplicando-se o método das Listas de Mackinnon (Mackinnon, 1991; Mackinnon e Phillips, 1993; Herzog et al., 2002; Ribon, 2010), adotando as recomendações de Herzog et al. (2002) e Brasil (2014a). Com base nessa metodologia, foi possível estimar o Índice de Frequência nas Listas (IFL), para cada espécie (Ribon, 2010):

$$
\mathrm{IFL}=\mathrm{n}(\mathrm{i}) / \mathrm{LM}
$$

Onde:

n(i) = número de vezes que a espécie foi registrada nas listas de 10 espécies; LM = número total de listas de Mackinnon.

A identificação das espécies foi realizada por detecção visual e manifestações sonoras (cantos, chamados, estalidos e batidas de asas). Para facilitar a visualização, foi utilizado binóculo prismático (Pentax ${ }^{\circledR} 8 \mathrm{X} 40$ ) e as vocalizações foram registradas com um 
smartphone (Motorola Moto GTM), S. O. Android, com o aplicativo Tape a Talk Pro 1.0.0.8 (by Markus Drösser), conforme descrito por Hidvegi e Delchambre (2013). Os cantos e/ou chamados foram editados no programa Audacity ${ }^{\circledR}$ 2.1.0. As vocalizações editadas e com identificação no nível de espécie ou subespécie foram depositadas nos bancos de vocalizações do website Xeno-Canto (http://www.xenocanto.org) e do website Wikiaves (https://www.wikiaves.com.br), respectivamente, bem como as fotos obtidas de indivíduos na natureza foram depositadas nesse último site. As vozes não identificadas foram submetidas à determinação por comparação com banco de vozes de Minns et al. (2010).

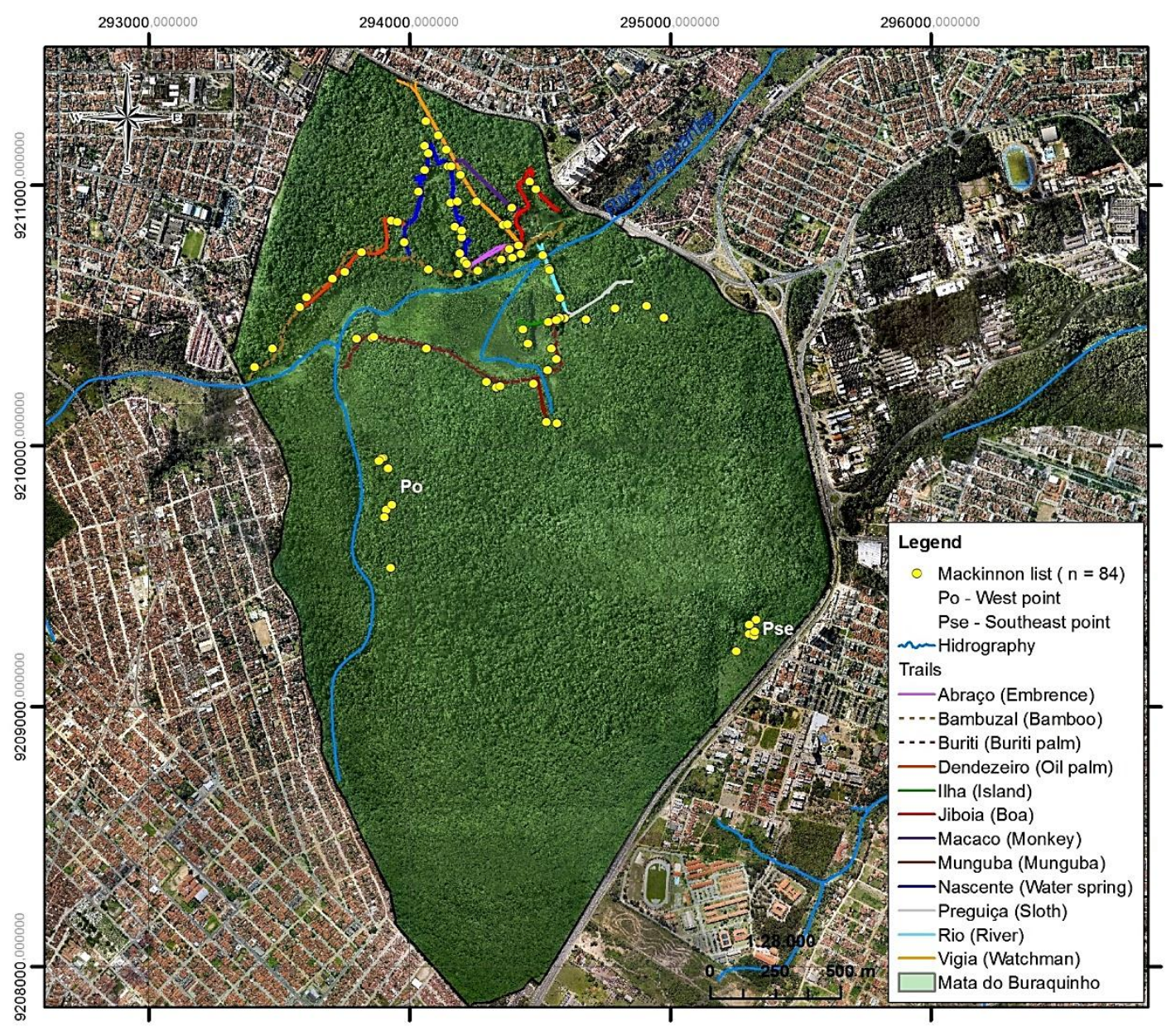

Figura 4. Trilhas, pontos Po e Pse; e pontos gerorreferenciados das listas de Mackinnon, na RVS Mata do Buraquinho. Fonte: Sistema Geodésico Brasileiro, Universal Transverse Mercator (UTM). SIRGAS 2000, zona 25 Sul. Aerofotos 2012. (Mapa Urbano Digital. Prefeitura Municipal de João Pessoa, Secretaria de Meio Ambiente, Diretoria de Estudos e Pesquisas. Técnico responsável Arinaldo Inácio das Neves, 02/02/2018).

Os registros das espécies foram anotados em planilhas de campo/listas das 10 espécies, adaptadas de Brasil (2014a) e Ribon (2010), com as especificações do local, data, hora início e final de cada lista, coordenadas UTM de cada lista concluída, nomes científicos (com epítetos abreviados, conforme sequência de Piacentini et al., 2015), e/ou vernaculares, forma de registro (acústico e/ou visual), estrato da vegetação (solo, sub-bosque, copa e vegetação aquática), comportamento/interação (forrageio, reprodução, agregado, solitário, bando misto). Como referência para os trabalhos de campo, foi utilizada uma lista base $(n=204)$ por ordem alfabética das espécies registradas 
para o Município de João Pessoa, a qual foi compilada a partir de Zenaide (1953), Dekeyser (1979), PMJP (2012), Alves et al. (2017), Wikiaves (2017; 2020), seguindo a nomenclatura de Piacentini et al. (2015).

Foram utilizados guias e literatura especializada para determinação das espécies registradas em campo, tais como Meyer de Schauensee (1970), Sick (1985; 1997), Dunning (1987) e Sigrist (2014). A identificação das espécies seguiu a nomenclatura e a ordem taxonômica da lista comentada das aves do Brasil, compilada pelo Comitê Brasileiro de Registros Ornitológicos (Piacentini et al., 2015). Os nomes subespecíficos seguiram a nomenclatura adotada por Pinto e Camargo (1961) e Pinto (1945 e 1978). Para os nomes populares foi considerado os apresentados por Piacentini et al. (2015) e Sick (1985; 1997).

Para a classificação do estado de conservação das espécies como endêmicas ou ameaçadas de extinção, foi adotada a Portaria MMA no 444/2014 (Brasil, 2014b) e os critérios adotados em Brasil (2005), com a lista das espécies da fauna brasileira ameaçadas de extinção e o Livro Vermelho da Fauna Brasileira (Brasil, 2008; Brasil, 2016) e categorias adotadas pela IUCN (2020). Para as categorias de sensibilidade aos distúrbios causados pelas atividades antrópicas, foi adaptada a classificação de Stotz et al. (1996), Sick (1997) e Brasil (2005), para os táxons ameaçados. Para a distribuição das espécies ameaçadas utilizou-se os registros disponíveis no Wikiaves (2020) e na literatura especializada (Meyer de Schauensee, 1970; Sick, 1985 e 1997; IUCN, 2020).

Os dados anotados nas planilhas de campo foram transferidos para planilhas eletrônicasdo Libre Office, previamente confeccionadas.

Para os exemplares citados, tanto de aves como de plantas adotou-se as abreviaturas: BMNH, British Museum of Natural History; MN, Museu Nacional do Rio de Janeiro; USNM, National Museum of Natural History (Smithsonian Institution); NYBG, New York Botanical Garden; JPB, Herbário Lauro Pires Xavier (UFPB, João Pessoa); EAC, Herbário Prisco Bezerra (UFCE, Fortaleza); ASE, Herbário da Universidade Federal de Sergipe (UFS, Aracaju).

\section{Resultados e discussão}

Foram obtidas 84 listas de Mackinnon, de 10 espécies e registradas 113 espécies de aves no presente estudo, representadas por 34 famílias, as mais abundantes em número de espécies foram Tyrannidae e Thraupidae, ambas com 15 (cada uma com 13,3\% do número total de espécies), Trochilidae $(\mathrm{n}=9 ; 8,0 \%)$, Accipitridae $(\mathrm{n}=7 ; 6,2 \%)$, Thamnophilidae $(n=5 ; 4,4 \%)$, Ardeidae $(n=5 ; 4,4 \%)$, Rhynchocyclidae $(n=4 ; 3,5 \%)$, Psittacidae e Columbidae, ambas com 4 espécies (cada uma com 3,5\% do número total de espécies). Essas nove famílias correspondem a $60 \%$ de todas as espécies registradas na comunidade de aves. Das 34 famílias, 10 foram representadas apenas por uma espécie (Tabela 2; Figura 5).

Tabela 2. Aves registradas na RVS Mata do Buraquinho, João Pessoa, Paraíba, Brasil. Março de 2017 a fevereiro de 2018. Táxons ameaçados com asterisco (*). IFL, Índice de Frequência nas Listas.

\begin{tabular}{|l|c|c|c|}
\hline Família/espécie & $\begin{array}{c}\text { Nome popular em } \\
\text { português }\end{array}$ & Nome em inglês & IFL \\
\hline Ardeidae Leach, 1820 & \multicolumn{3}{|c|}{} \\
\hline Tigrisoma lineatum (Boddaert, 1783) & Socó-boi & Rufescent tiger-heron & 0,024 \\
\hline Butorides striata (Linnaeus, 1758) & Socozinho & Striated heron & 0,036 \\
\hline Bubulcus ibis (Linnaeus, 1758) & Garça-vaqueira & Cattle egret & 0,024 \\
\hline Ardea alba Linnaeus, 1758 & Garça-branca & Great egret & 0,024 \\
\hline Egretta thula (Molina, 1782) & Garça-branca-pequena & Snowy egret & 0,012 \\
\hline
\end{tabular}


Tabela 2. Continuação.

\begin{tabular}{|c|c|c|c|}
\hline Família/espécie & $\begin{array}{c}\text { Nome popular em } \\
\text { português }\end{array}$ & Nome em inglês & IFL \\
\hline \multicolumn{4}{|l|}{ Cathartidae Lafresnaye, 1839} \\
\hline Cathartes aura (Linnaeus, 1758) & Urubu de-cabeça-vermelha & Turkey vulture & 0,107 \\
\hline Cathartes burrovianus Cassin, 1845 & Urubu-de-cabeça-amarela & $\begin{array}{l}\text { Lesser yellow-headed } \\
\text { vulture }\end{array}$ & 0,012 \\
\hline Coragyps atratus (Bechstein, 1793) & Urubu & Black vulture & 0,107 \\
\hline \multicolumn{4}{|l|}{ Accipitridae Vigors, 1824} \\
\hline Leptodon forbesi (Swann, 1922)* & Gavião-gato-do-nordeste & White-collared kite & 0,024 \\
\hline $\begin{array}{l}\text { Chondrohierax uncinatus (Temminck, } \\
\text { 1822) }\end{array}$ & Caracoleiro & Hook-billed kite & 0,012 \\
\hline Ictinia plumbea (Gmelin, 1788) & Sovi & Plumbeous kite & 0,012 \\
\hline Urubitinga urubitinga (Gmelin, 1788) & Gavião-preto & Great black hawk & 0,024 \\
\hline Rupornis magnirostris (Gmelin, 1788) & Gavião-carijó & Roadside hawk & 0,155 \\
\hline Buteo nitidus (Latham, 1790 ) & Gavião-pedrês & Gray-lined hawk & 0,012 \\
\hline Buteo brachyurus Vieillot, 1816 & Gavião-de-cauda-curta & Short-tailed hawk & 0,095 \\
\hline \multicolumn{4}{|l|}{ Aramidae Bonaparte, 1852} \\
\hline Aramus guarauna (Linnaeus, 1766 ) & Carão & Limpkin & 0,071 \\
\hline \multicolumn{4}{|l|}{ Rallidae Rafinesque, 1815} \\
\hline Aramides cajaneus (Statius Muller, 1776) & Saracura-três-potes & Gray-necked wood-rail & 0,167 \\
\hline Porphyrio martinicus (Linnaeus, 1766) & Frango-d'água-azul & Purple gallinule & 0,012 \\
\hline \multicolumn{4}{|l|}{ Charadriidae Leach, 1820} \\
\hline Vanellus chilensis (Molina, 1782) & Quero-quero & Southern lapwing & 0,036 \\
\hline Jacanidae Chenu \& Des Murs, 1854 & & & 0,000 \\
\hline Jacana jacana (Linnaeus, 1766) & Jaçanã & Wattled jacana & 0,024 \\
\hline \multicolumn{4}{|l|}{ Columbidae Leach, 1820} \\
\hline Columbina talpacoti (Temminck, 1810) & Rolinha & Ruddy ground-dove & 0,048 \\
\hline Patagioenas speciosa (Gmelin, 1789) & Pomba-trocal & Scaled pigeon & 0,071 \\
\hline $\begin{array}{l}\text { Leptotila rufaxilla (Richard \& Bernard, } \\
\text { 1792) }\end{array}$ & Juriti-de-testa-branca & Gray-fronted Dove & 0,167 \\
\hline Geotrygon montana (Linnaeus, 1758) & Pariri & Ruddy quail-dove & 0,012 \\
\hline \multicolumn{4}{|l|}{ Cuculidae Leach, 1820} \\
\hline Piaya cayana (Linnaeus, 1766) & Alma-de-gato & Squirrel cuckoo & 0,226 \\
\hline Crotophaga ani Linnaeus, 1758 & Anu-preto & Smooth-billed ani & 0,048 \\
\hline Guira guira (Gmelin, 1788) & Anu-branco & Guira cuckoo & 0,012 \\
\hline \multicolumn{4}{|l|}{ Strigidae Leach, 1820} \\
\hline Athene cunicularia (Molina, 1782) & Coruja-buraqueira & Burrowing owl & 0,012 \\
\hline \multicolumn{4}{|l|}{ Caprimulgidae Vigors, 1825} \\
\hline Lurocalis semitorquatus (Gmelin, 1789) & Tuju & Short-tailed nighthawk & 0,012 \\
\hline Nyctidromus albicollis (Gmelin, 1789) & Bacurau & Common pauraque & 0,024 \\
\hline \multicolumn{4}{|l|}{ Apodidae Olphe-Galliard, 1887} \\
\hline Chaetura meridionalis Hellmayr, 1907 & Andorinhão-do-temporal & Sick's swift & 0,012 \\
\hline Tachornis squamata (Cassin, 1853) & Andorinhão-do-buriti & Fork-tailed palm-swift & 0,012 \\
\hline \multicolumn{4}{|l|}{ Trochilidae Vigors, 1825} \\
\hline Glaucis hirsutus (Gmelin, 1788) & Balança-rabo-de-bico-torto & Rufous-breasted hermit & 0,048 \\
\hline Phaethornis ruber (Linnaeus, 1758) & Rabo-branco-rubro & Reddish hermit & 0,155 \\
\hline $\begin{array}{l}\text { Phaethornis pretrei (Lesson \& Delattre, } \\
\text { 1839) }\end{array}$ & Rabo-branco-acanelado & Planalto hermit & 0,012 \\
\hline Eupetomena macroura (Gmelin, 1788) & Beija-flor-tesoura & Swallow-tailed hummingbird & 0,119 \\
\hline Chrysolampis mosquitus (Linnaeus, 1758) & Beija-flor-vermelho & Ruby-topaz hummingbird & 0,012 \\
\hline Chlorestes notata (Reich, 1793) & Beija-flor-de-garganta-azul & Blue-chinned sapphire & 0,060 \\
\hline Chlorostilbon lucidus (Shaw, 1812) & $\begin{array}{c}\text { Besourinho-de-bico- } \\
\text { vermelho }\end{array}$ & Glittering-bellied emerald & 0,048 \\
\hline Amazilia leucogaster (Gmelin, 1788) & Beija-flor-de-barriga-branca & Plain-bellied emerald & 0,190 \\
\hline Amazilia fimbriata (Gmelin, 1788) & Beija-flor-de-garganta-verde & $\begin{array}{l}\text { Glittering-throated } \\
\text { emerald }\end{array}$ & 0,071 \\
\hline \multicolumn{4}{|l|}{ Alcedinidae Rafinesque, 1815} \\
\hline Megaceryle torquata (Linnaeus, 1766 ) & Martim-pescador-grande & Ringed kingfisher & 0,012 \\
\hline Chloroceryle amazona (Latham, 1790) & Martim-pescador-verde & Amazon kingfisher & 0,024 \\
\hline Chloroceryle americana (Gmelin, 1788) & Martim-pescador-pequeno & Green kingfisher & 0,036 \\
\hline
\end{tabular}

Rev. Bras. Gest. Amb. Sustent., 2021, vol. 8, n. 18, p. 37-75. 
Tabela 2. Continuação.

\begin{tabular}{|c|c|c|c|}
\hline Família/espécie & $\begin{array}{c}\text { Nome popular em } \\
\text { português }\end{array}$ & Nome em inglês & IFL \\
\hline \multicolumn{4}{|l|}{ Galbulidae Vigors, 1825} \\
\hline Galbula ruficauda Cuvier, 1816 & Ariramba & Rufous-tailed jacamar & 0,131 \\
\hline \multicolumn{4}{|l|}{ Picidae Leach, 1820} \\
\hline Picumnus pernambucensis Zimmer, 1947 & $\begin{array}{l}\text { Picapauzinho-de- } \\
\text { pernambuco }\end{array}$ & Pernambuco piculet & 0,262 \\
\hline Veniliornis passerinus (Linnaeus, 1766) & Pica-pau-pequeno & Little woodpecker & 0,214 \\
\hline Dryocopus lineatus (Linnaeus, 1766) & Pica-pau-de-banda-branca & Lineated woodpecker & 0,024 \\
\hline \multicolumn{4}{|l|}{ Falconidae Leach, 1820} \\
\hline Caracara plancus (Miller, 1777) & Carcará & Southern caracara & 0,071 \\
\hline Milvago chimachima (Vieillot, 1816) & Carrapateiro & Yellow-headed caracara & 0,024 \\
\hline \multicolumn{4}{|l|}{ Psittacidae Rafinesque, 1815} \\
\hline Diopsittaca nobilis (Linnaeus, 1758) & Maracanã-pequena & Red-shouldered macaw & 0,119 \\
\hline Forpus xanthopterygius (Spix, 1824) & tuim & Blue-winged parrotlet & 0,048 \\
\hline Touit surdus (Kuhl, 1820)* & Apuim-de-cauda-amarela & Golden-tailed parrotlet & 0,060 \\
\hline Amazona amazonica (Linnaeus, 1766) & curica & Orange-winged parrot & 0,131 \\
\hline \multicolumn{4}{|l|}{ Thamnophilidae Swainson, 1824} \\
\hline Myrmotherula axillaris (Vieillot, 1817) & Choquinha-de-flanco-branco & White-flanked antwren & 0,262 \\
\hline Formicivora grisea (Boddaert, 1783) & Papa-formiga-pardo & White-fringed antwren & 0,036 \\
\hline Dysithamnus mentalis (Temminck, 1823) & Choquinha-lisa & Plain antvireo & 0,060 \\
\hline Herpsilochmus atricapillus Pelzeln, 1868 & Chorozinho-de-chapéu-preto & Black-capped Antwren & 0,202 \\
\hline $\begin{array}{ll}\text { Herpsilochmus } & \text { rufimarginatus } \\
\text { (Temminck, 1822) } & \end{array}$ & Chorozinho-de-asa-vermelha & Rufous-winged antwren & 0,060 \\
\hline \multicolumn{4}{|l|}{ Dendrocolaptidae Gray, 1840} \\
\hline Xiphorhynchus atlanticus (Cory, 1916)* & Arapaçu-rajado-do-nordeste & $\begin{array}{l}\text { Northern lesser } \\
\text { woodcreeper }\end{array}$ & 0,250 \\
\hline \multicolumn{4}{|l|}{ Xenopidae Bonaparte, 1854} \\
\hline Xenops minutus alagoanus Pinto, 1954* & Bico-virado-miúdo & Plain xenops & 0,202 \\
\hline \multicolumn{4}{|l|}{ Furnariidae Gray, 1840} \\
\hline Certhiaxis cinnamomeus (Gmelin, 1788) & Curutié & Yellow-chinned spinetail & 0,012 \\
\hline \multicolumn{4}{|l|}{ Pipridae Rafinesque, 1815} \\
\hline Neopelma pallescens (Lafresnaye, 1853) & Fruxu-do-cerradão & Pale-bellied tyrant-manakin & 0,190 \\
\hline Chiroxiphia pareola (Linnaeus, 1766) & Tangará-príncipe & Blue-backed manakin & 0,274 \\
\hline \multicolumn{4}{|l|}{ Tityridae Gray, 1840} \\
\hline Iodopleura pipra leucopygia Salvin, $1885^{*}$ & Anambezinho & Buff-throated purpletuft & 0,060 \\
\hline $\begin{array}{l}\text { Pachyramphus polychopterus (Vieillot, } \\
1818 \text { ) }\end{array}$ & Caneleiro-preto & White-winged becard & 0,036 \\
\hline \multicolumn{4}{|l|}{ Rhynchocyclidae Berlepsch, 1907} \\
\hline $\begin{array}{l}\text { Leptopogon amaurocephalus Tschudi, } \\
1846\end{array}$ & Cabeçudo & Sepia-capped flycatcher & 0,024 \\
\hline Tolmomyias flaviventris (Wied, 1831) & Bico-chato-amarelo & Yellow-breasted flycatcher & 0,155 \\
\hline Todirostrum cinereum (Linnaeus, 1766) & Ferreirinho-relógio & Common tody-flycatcher & 0,262 \\
\hline $\begin{array}{l}\text { Hemitriccus griseipectus naumburgae } \\
\text { (Zimmer, 1945)* }\end{array}$ & Maria-de-barriga-branca & White-bellied tody-tyrant & 0,190 \\
\hline \multicolumn{4}{|l|}{ Tyrannidae Vigors, 1825} \\
\hline Zimmerius acer (Salvin \& Godman, 1883) & Poiaeiro-da-guiana & Guianan tyrannulet & 0,012 \\
\hline Ornithion inerme Hartlaub, 1853 & Poiaeiro-de-sobrancelha & White-lored tyrannulet & 0,012 \\
\hline $\begin{array}{lll}\text { Camptostoma obsoletum (Temminck, } \\
1824)\end{array}$ & Risadinha & $\begin{array}{c}\text { Southern beardless- } \\
\text { tyrannulet }\end{array}$ & 0,024 \\
\hline Elaenia flavogaster (Thunberg, 1822) & $\begin{array}{l}\text { Guaracava-de-barriga- } \\
\text { amarela }\end{array}$ & Yellow-bellied elaenia & 0,143 \\
\hline Phaeomyias murina (Spix, 1825) & Bagageiro & Mouse-colored tyrannulet & 0,012 \\
\hline Phyllomyias fasciatus (Thunberg, 1822) & Piolhinho & Planalto tyrannulet & 0,012 \\
\hline Legatus leucophaius (Vieillot, 1818) & Bem-te-vi-pirata & Piratic flycatcher & 0,048 \\
\hline Myiarchus ferox (Gmelin, 1789) & Maria-cavaleira & Short-crested flycatcher & 0,012 \\
\hline Pitangus sulphuratus (Linnaeus, 1766) & Bem-te-vi & Great kiskadee & 0,274 \\
\hline Megarynchus pitangua (Linnaeus, 1766) & Neinei & Boat-billed flycatcher & 0,024 \\
\hline Myiozetetes similis (Spix, 1825) & $\begin{array}{l}\text { Bentevizinho-de-penacho- } \\
\text { vermelho }\end{array}$ & Social flycatcher & 0,119 \\
\hline Tyrannus melancholicus Vieillot, 1819 & Suiriri & Tropical kingbird & 0,179 \\
\hline
\end{tabular}


Tabela 2. Continuação.

\begin{tabular}{|c|c|c|c|}
\hline Família/espécie & $\begin{array}{c}\text { Nome popular em } \\
\text { português }\end{array}$ & Nome em inglês & IFL \\
\hline Empidonomus varius (Vieillot, 1818) & Peitica & Variegated flycatcher & 0,012 \\
\hline $\begin{array}{l}\text { Myiophobus fasciatus (Statius Muller, } \\
\text { 1776) }\end{array}$ & Filipe & Bran-colored flycatcher & 0,071 \\
\hline Fluvicola nengeta (Linnaeus, 1766) & Lavadeira-mascarada & Masked water-tyrant & 0,024 \\
\hline \multicolumn{4}{|l|}{ Vireonidae Swainson, 1837} \\
\hline Cyclarhis gujanensis (Gmelin, 1789) & Pitiguari & $\begin{array}{l}\text { Rufous-browed } \\
\text { peppershrike }\end{array}$ & 0,190 \\
\hline Vireo chivi (Vieillot, 1817) & Juruviara & Chivi vireo & 0,321 \\
\hline \multicolumn{4}{|l|}{ Hirundinidae Rafinesque, 1815} \\
\hline Pygochelidon cyanoleuca (Vieillot, 1817) & Andorinha-pequena-de-casa & Blue-and-white swallow & 0,024 \\
\hline Stelgidopteryx ruficollis (Vieillot, 1817) & Andorinha-serradora & $\begin{array}{l}\text { Southern rough-winged } \\
\text { swallow }\end{array}$ & 0,060 \\
\hline Tachycineta albiventer (Boddaert, 1783) & Andorinha-do-rio & White-winged swallow & 0,024 \\
\hline \multicolumn{4}{|l|}{ Troglodytidae Swainson, 1831} \\
\hline Troglodytes musculus Naumann, 1823 & Corruíra & Southern house wren & 0,119 \\
\hline $\begin{array}{ll}\begin{array}{l}\text { Pheugopedius genibarbis } \\
\text { 1838) }\end{array} & \\
\end{array}$ & Garrinchão-pai-avô & Moustached wren & 0,024 \\
\hline \multicolumn{4}{|l|}{ Polioptilidae Baird, 1858} \\
\hline Ramphocaenus melanurus Vieillot, 1819 & Chirito & Long-billed gnatwren & 0,012 \\
\hline Polioptila plumbea (Gmelin, 1788) & $\begin{array}{l}\text { Balança-rabo-de-chapéu- } \\
\text { preto }\end{array}$ & Tropical gnatcatcher & 0,190 \\
\hline \multicolumn{4}{|l|}{ Turdidae Rafinesque, 1815} \\
\hline Turdus leucomelas Vieillot, 1818 & Sabiá-branco & Pale-breasted thrush & 0,286 \\
\hline \multicolumn{4}{|l|}{ Passerellidae Cabanis \& Heine, 1850} \\
\hline Arremon taciturnus (Hermann, 1783) & Tico-tico-de-bico-preto & Pectoral sparrow & 0,012 \\
\hline \multicolumn{4}{|l|}{ Thraupidae Cabanis, 1847} \\
\hline Tangara sayaca (Linnaeus, 1766) & Sanhaço-cinzento & Sayaca tanager & 0,202 \\
\hline Tangara palmarum (Wied, 1821) & Sanhaço-do-coqueiro & Palm tanager & 0,310 \\
\hline Tangara cayana (Linnaeus, 1766 ) & Saíra-amarela & Burnished-buff tanager & 0,167 \\
\hline Nemosia pileata (Boddaert, 1783) & Saíra-de-chapéu-preto & Hooded tanager & 0,024 \\
\hline Hemithraupis guira (Linnaeus, 1766) & Saíra-de-papo-preto & Guira tanager & 0,036 \\
\hline Volatinia jacarina (Linnaeus, 1766) & Tiziu & Blue-black grassquit & 0,012 \\
\hline Lanio cristatus (Linnaeus, 1766) & Tiê-galo & Flame-crested tanager & 0,190 \\
\hline Tachyphonus rufus (Boddaert, 1783) & Pipira-preta & White-lined tanager & 0,012 \\
\hline Ramphocelus bresilius (Linnaeus, 1766) & Tiê-sangue & Brazilian tanager & 0,107 \\
\hline Cyanerpes cyaneus (Linnaeus, 1766) & Saíra-beija-flor & Red-legged honeycreeper & 0,083 \\
\hline Dacnis cayana (Linnaeus, 1766 ) & Saí-azul & Blue dacnis & 0,155 \\
\hline Coereba flaveola (Linnaeus, 1758) & Cambacica & Bananaquit & 0,333 \\
\hline Sporophila angolensis (Linnaeus, 1766) & Curió & Chestnut-bellied seed-finch & 0,012 \\
\hline Saltator maximus (Statius Muller, 1776) & Tempera-viola & Buff-throated saltator & 0,048 \\
\hline \begin{tabular}{lcc|} 
Thlypopsis sordida & (d'Orbigny \\
Lafresnaye, 1837) & & \\
\end{tabular} & Saí-canário & Orange-headed tanager & 0,012 \\
\hline \multicolumn{4}{|l|}{ Fringillidae Leach, 1820} \\
\hline Euphonia chlorotica (Linnaeus, 1766) & Fim-fim & Purple-throated euphonia & 0,202 \\
\hline Euphonia violacea (Linnaeus, 1758) & Gaturamo & Violaceous euphonia & 0,071 \\
\hline
\end{tabular}

Resultados semelhantes ou relativamente próximos dos obtidos no presente estudo têm sido encontrados em estudos sobre composição de avifauna em outros remanescentes de Mata Atlântica no nordeste do Brasil (Brasil, 2005; Almeida e Teixeira, 2010; PMJP, 2012). Cabendo citar Ruiz-Esparza et al. (2015), em Sergipe (Mata do Junco, Refúgio Estadual de Vida Silvestre, Capela), com esforço de campo de $3.400 \mathrm{~h}$ de rede de neblina e 100 listas de Mackinnon, obtiveram 129 espécies de aves, 41 famílias, 18 espécies de Tyrannidae, 14 Thraupidae, 8 Trochilidae, 7 Rhynchocyclidae e 6 Thamnophilidae; e Enedino et al. (2018) estudou nove remanescentes florestais na Região Metropolitana de João Pessoa, com um de total 450 listas de Mackinnon, sendo obtidas 50 
listas para cada fragmento estudado, o que resultou em uma lista de 126 espécies, representadas por 41 famílias, com 16 espécies para Tyrannidae e Thraupidae, 8 Trochilidae, 6 Thamnophilidae e 5 de Rhynchocyclidae e Columbidae, demostrando similaridade entre os resultados obtidos no presente estudo, quanto ao número de espécies por família, o qual foi baseado em 84 listas de Mackinnon.

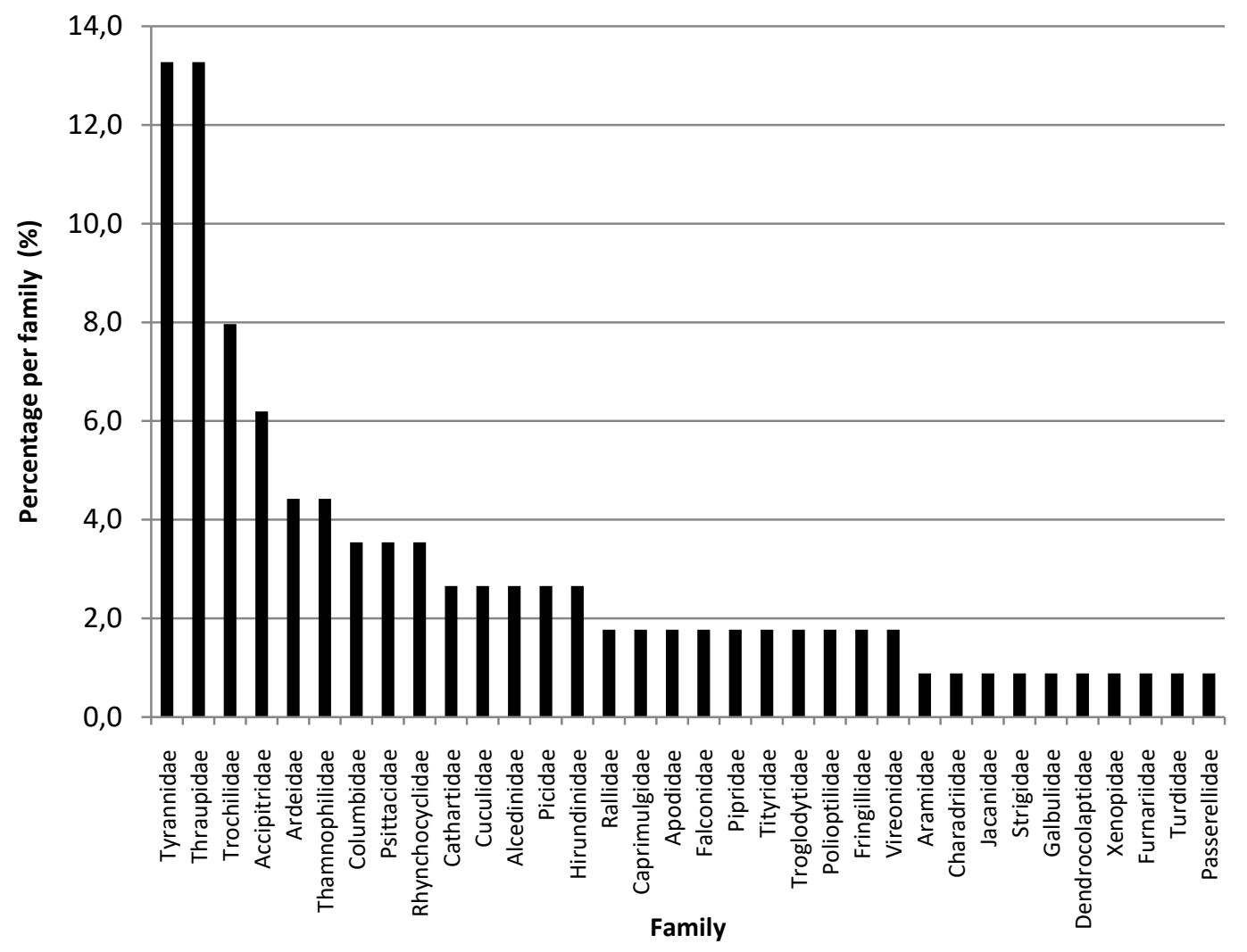

Figura 5. Representatividade por famílias, da riqueza de espécies de aves na RVS Mata do Buraquinho, João Pessoa, Paraíba, Brasil. Março de 2017 a fevereiro de 2018.

As dez espécies mais frequentes nas listas de Mackinnon (IFL) foram Coereba flaveola (0,333); Vireo chivi (0,321), Tangara palmarum $(0,310)$, Turdus leucomelas $(0,286)$, Chiroxiphia pareola $(0,274)$, Pitangus sulphuratus $(0,274)$, Picumnus pernambucensis $(0,262)$, Myrmotherula axillaris $(0,262)$, Todirostrum cinereum $(0,262)$ e Xiphorhynchus atlanticus $(0,250)$. A espécie $X$. atlanticus também foi observada em bandos mistos ao lado de Xenops minutus alagoanus $(0,202)$ e Hemitriccus griseipectus naumburgae $(0,190)$, sendo essa última com IFL inferior a 0,202, por apresentar, provavelmente, pequenos territórios distribuídos em diversos sítios da área de estudo.

Na comunidade de aves, 28 espécies são consideradas indicadoras de alterações de habitat, tal como em florestas secundárias (Ruiz-Esparza et al., 2015), tais como Coragyps atratus, Vanellus chilensis, Columbina talpacoti, Crotophaga ani, Guira guira, Nyctidromus albicollis, Eupetomena macroura, Todirostrum cinereum, Piaya cayana, Camptostoma obsoletum, Elaenia flavogaster, Phaeomyias murina, Myiarchus ferox, Pitangus sulphuratus, Megarynchus pitangua, Myiozetetes similis, Tyrannus melancholicus, Stelgidopteryx ruficollis, Turdus leucomelas, Coereba flaveola, Saltator maximus, Ramphocelus bresilius, Tangara sayaca, Tangara palmarum, Dacnis cayana, Cyanerpes cyaneus, Volatinia jacarina e Euphonia chlorotica, cabendo ressaltar que ao lado dessa última espécie tem sido registrado Iodopleura pipra leucpopygia, por partilharem dos mesmos recursos 
alimentares. Ressalta-se a presença de Formicivora grisea $(\mathrm{IFL}=0,036)$, exclusivamente no ponto Pse, onde se trata de uma macha relativamente pequena de ecótono (zona de tensão ecológica, ver Brasil, 1981) da Floresta Estacional Semidecidual com a savana ("cerrado"), com efeito de borda; tendo em vista que esse Thamnophilidae, mesmo apresentando larga distribuição geográfica, tem como habitat preferencial áreas com vegetação mais xerófila, tal como cerrado e florestas decíduas. Pode ser tratado como bioindicador tendo em vista sua preferência por essa área remanescente com fisionomia similar ao habitat original e por fim persistindo na ocupação dessa área alterada; outra espécie presente exclusivamente nesse ponto foi Chrysolampis mosquitus (IFL = 0,012).

Foram registrados oito táxons endêmicos do Brasil e do Bioma Mata Atlântica, no Centro de Endemismo Pernambuco (CEP), cinco espécies e três subespécies, foram elas, Picumnus pernambucensis, Touit surdus, Xiphorhynchus atlanticus, Xenops minutus alagoanus, Iodopleura pipra leucopygia, Hemitriccus griseipectus naumburgae, Ramphocelus bresilius, sendo que Leptodon forbesi, já foi registrado fora do CEP (Pereira et al., 2014). Destas, seis táxons estão ameaçadas de extinção em diferentes categorias de ameaças (Brasil, 2018b; IUCN, 2020) (Tabela 3; Figura 6).

Tabela 3. Espécies ameaçadas registradas na RVS Mata do Buraquinho. M, média; H, alta.

\begin{tabular}{|l|l|c|c|c|}
\hline \multirow{2}{*}{ Táxon } & Categoria de ameaça & \multicolumn{2}{|c|}{$\begin{array}{c}\text { Sensibilidade à } \\
\text { perturbação }\end{array}$} \\
\cline { 2 - 5 } & \multicolumn{1}{|c|}{ MMA $^{\mathbf{1}}$} & IUCN $^{2}$ & $\begin{array}{c}\text { Stotz et al., } \\
\mathbf{1 9 9 6}\end{array}$ & $\begin{array}{c}\text { Brasil, } \\
\mathbf{2 0 0 5}\end{array}$ \\
\hline Leptodon forbesi (Swann, 1922) & EN 2a(ii) & EN & $\mathrm{M}^{* *}$ & - \\
\hline Touit surdus (Kuhl, 1820) & VU C2a(i) & VU & $\mathrm{H}-$ & - \\
\hline Xiphorhynchus atlanticus (Cory, 1916) & VU C2a(i) & - & $\mathrm{H}^{*}$ & alta \\
\hline Xenops minutus alagoanus Pinto, 1954 & VU B2ab(iii) & - & $\mathrm{M}^{* *}$ & - \\
\hline Iodopleura pipra leucopygia Salvin, 1885 & CR C2a(i) & - & $\mathrm{M}^{* *}$ & - \\
\hline Hemitriccus griseipectus naumburgae (Zimmer, 1945) & VU 2ab(iii) & - & $\mathrm{M}^{* *}$ & alta \\
\hline
\end{tabular}

${ }^{1}$ Brasil (2018b); ${ }^{2}$ IUCN (2020), ameaça global; **Espécies e subespécies endêmicas com sensibilidade subestimada ou pouco conhecida.

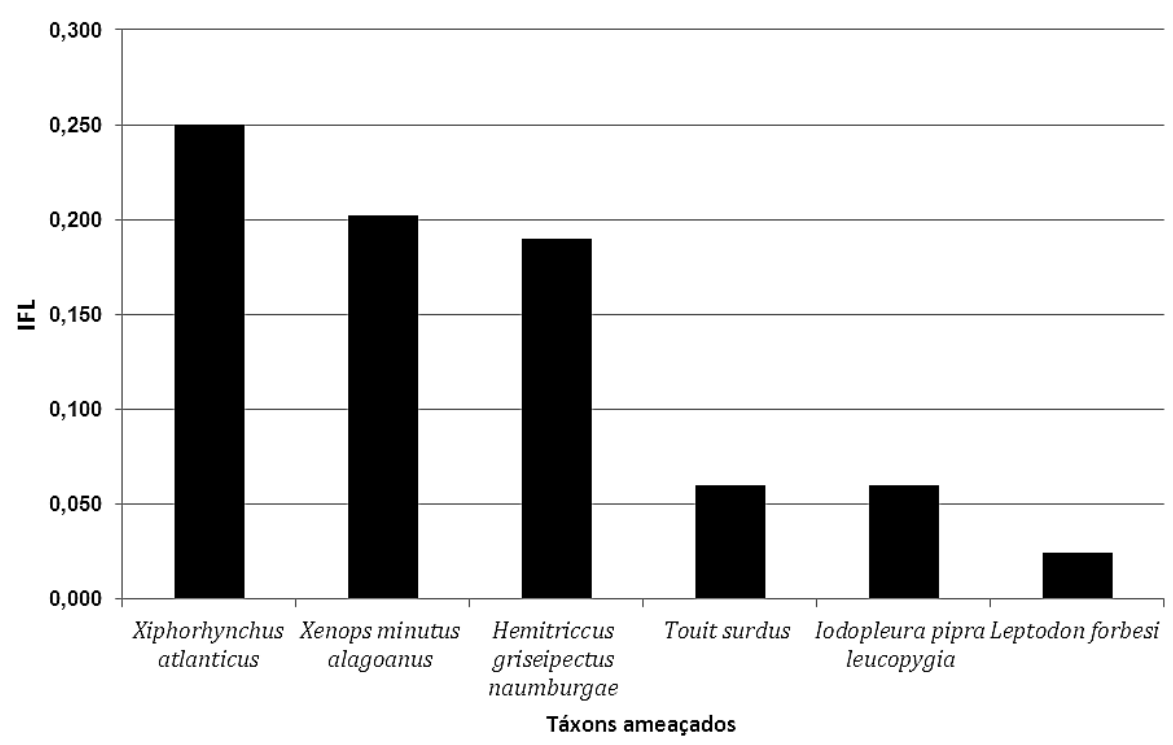

Figura 6. Índices de Frequência nas Listas (IFL) dos táxons ameaçados de extinção registrados na RVS Mata do Buraquinho, João Pessoa, Paraíba, Brasil. Março de 2017 a fevereiro de 2018. 
O Brasil possui 1.919 espécies de aves, porém considerando-se que desse conjunto 910 são politípicas - 1.009 taxa, assim temos 2.042 subespécies, com isso o país tem 3.051 taxano grupo aves (Piacentini et al., 2015).

O Bioma Mata Atlântica apresenta 598 espécies da fauna ameaçada, sendo que dessas 428 são endêmicas do bioma, aproximadamente $71,6 \%$ de todas as espécies da fauna desse bioma, as aves estão representadas por 234 espécies ameaçadas em diferentes categorias de ameaça, com cerca de $39 \%$ de todas as espécies da Mata Atlântica (ver Brasil, 2016, p. 8-9). Após as atividades agropecuárias o processo de expansão urbana, com perda ou degradação do habitat é a segunda maior ameaça à fauna brasileira, afetando um número significativo de espécies, de cerca de 300 espécies (Brasil, 2016, p. 10). No Livro Vermelho da Fauna Brasileira Ameaçada de Extinção constam as informações sobre os critérios de avaliação das ameaças (Brasil, 2018a).

Há registro de 434 espécies de aves para o Centro de Endemismo Pernambuco (CEP), sendo que destas 40 táxons estão incluídos em diferentes categorias de ameaça de extinção (Roda et al., 2011). Cabendo destacar que, dentre as espécies ameaçadas de extinção do CEP, seis foram registradas no presente levantamento nesse fragmento de Mata Atlântica, na área urbana do Município de João Pessoa (PB).

\section{Leptodon forbesi (Swann, 1922) \\ Gavião-gato-do-nordeste \\ White-collared kite}

0 L. forbesi, com cerca de 45,7 a 50,8 cm de comprimento, distingue-se de L. cayanensis, pela cor branca do colar atrás da cabeça, ao invés de cinza médio a pálido discreto; principalmente pelas coberteiras inferiores das asas brancas, ao invés de todas negras; e sob a superfície das penas secundárias totalmente de cor branca, com barras pretas muito reduzidas em relação às demais (Pereira et al., 2006; Dénes et al., 2011) (Figura 7).

Ocorre no nordeste do Brasil, com 82,5\% das ocorrências em localidades dos Estados de Pernambuco e Alagoas, são elas, Pernambuco (Abreu e Lima, Barreiros, Bonito, Camaragibe, Gravatá, Jaqueira, Lagoa dos Gatos, Maraial, Pau d'Alho, Paulista, Recife, Rio Formoso, São Benedito do Sul, São José da Coroa Grande, São Vicente Férrer, Sirinhaém, Timbaúba); Alagoas (Coruripe, Ibateguara, Junqueiro, Maceió, Messias, Murici, Passo de Camaragibe, Pindoba, Rio Largo, Roteiro, São José da Laje e São Miguel dos Campos); Sergipe (Santa Luzia do Itanhy, Serra de Itabaiana, Itabaiana), norte da Bahia e sul do Rio Grande do Norte; Paraíba (Conde, Santa Rita, João Pessoa, Mamanguape, Rio Tinto, Sapé e Areia) (Almeida e Teixeira, 2010; Pereira et al., 2014; Pereira et al., 2019; IUCN, 2020).

Quanto ao registro de Amadonastur lacernulatus (Temminck, 1827) [=Leucopternis larcernulata (Temminck, 1827)], em Mamanguape/Rio Tinto (PB), na Reserva Biológica Guaribas, por Almeida e Teixeira (2010), tratou-se de uma identificação visual de um indivíduo pousado que recentemente foi validado como Leptodon forbesi por Pereira et al. (2019); à época, pouco se conhecia da taxonomia e distribuição espacial dessa espécie no Nordeste do Brasil, exceto pela informação da "redescoberta" da espécie apresentada por Teixeira et al. (1987), como uma espécie válida e não "aberrante jovem" de L. cayanensis (Latham, 1790), com a qual apresenta grande semelhança. Outra identificação de um gavião com características semelhantes a L. forbesi, foi realizada na Mata do Buraquinho (João Pessoa, PB) por Zenaide (1953) como Amadonastur lacernulatus (=Leucopternis larcernulata), também equivocada, mas que atestou a presença de L. forbesi nesse remanescente florestal nos anos de 1950. Sendo assim, indica-se que quaisquer outros estudos e trabalhos de campo, devem cercar-se de cautela, os quais devem considerar as características diagnósticas detalhadas e preferencialmente com contato visual documentado (por exemplo, fotografia) em campo, evidenciando as partes inferiores da espécie, particularmente em voo, o que difere significativamente de A.lacernulatus (Figuras 7 e 8). 
Apresenta "média" sensibilidade a distúrbios ambientais; relativamente raro; habita ecossistemas florestais, como a Floresta Estacional Semidecidual das terras baixas (77,5\% das ocorrências) e ombrófilas abertas (ver Brasil, 1981; Pereira et al., 2019), na Mata Atlântica, no litoral do Nordeste do Brasil, ocupando uma área florestal de cerca de $1.636,89 \mathrm{~km}^{2}$, com fragmentos maior que 100 ha $\left(1 \mathrm{~km}^{2}\right)$ e apenas está em $241 \mathrm{~km}^{2}$ de áreas legalmente protegidas (Pereira et al., 2019). Essa espécie está ameaçada pelo intenso desmatamento, necessitando de prioridade urgente tanto para a conservação in situ, pesquisas de campo (Stotz et al., 1996) e conservação ex situ, programa de criação em cativeiro (Pereira et al., 2014) e restauração florestal, a fim de reconectar os fragmentos florestais representativos, particularmente àqueles que compõem as matas ciliares e ao longo de pequenos riachos (Pereira et al., 2019). A espécie está contemplada no Plano de Ação Nacional (PAN) para Conservação das Aves da Mata Atlântica e no Plano de Ação Nacional para a Conservação das Aves da Caatinga (Brasil, 2018b, p. 111; Brasil, 2018c).

Foram realizados quatro registros fotográficos da espécie na RVS Mata do Buraquinho, entre 2011 e 2014 (Lees, 2011; Lo, 2013; Sousa, 2014; Lima, 2014; Figura 8) e não diferente ao longo dos trabalhos de campo do presente estudo, no qual apresentou uma das mais baixas freqüências (IFL $=0,024$ ) na comunidade de aves estudada e a mais baixa entre as espécies ameaçadas. Pereira et al. (2014) aponta uma virtual persistência dessa espécie em fragmentos florestais pequenos e degradados, sugerindo resiliência à perda de habitat florestal. Porém, somente estudos de densidade populacional, por meio de censos, podem verificar essa hipótese, bem como estudos de autoecologia podem garantir informações consistentes sobre essa espécie, sobre comportamento, biologia, movimentos sazonais e de circulação entre os fragmentos do entorno da RVS, como tem sido observado no Campus I, da UFPB (ver Callado, 2021).

Durante os trabalhos de campo na RVS, Leptodon forbesi demonstrou ser uma espécie pouco conspícua, de difícil detecção visual (coordenadas UTM 294118.3400; 9211175.6531; zona 25M) e muito menos vocal, o que dificulta sobremaneira qualquer tentativa de avaliação preliminar de sua ocorrência nos remanescentes florestais do município. Tal característica dessa espécie demanda pela elaboração de um plano de estudo específico, com maior esforço de campo e a possibilidade da utilização de torres de observação, com alcance acima das copas das árvores emergentes, onde possivelmente é o estrato de preferência desse gavião, conforme os registros atestam, tais como copas de árvores altas ou sobrevoando-as.

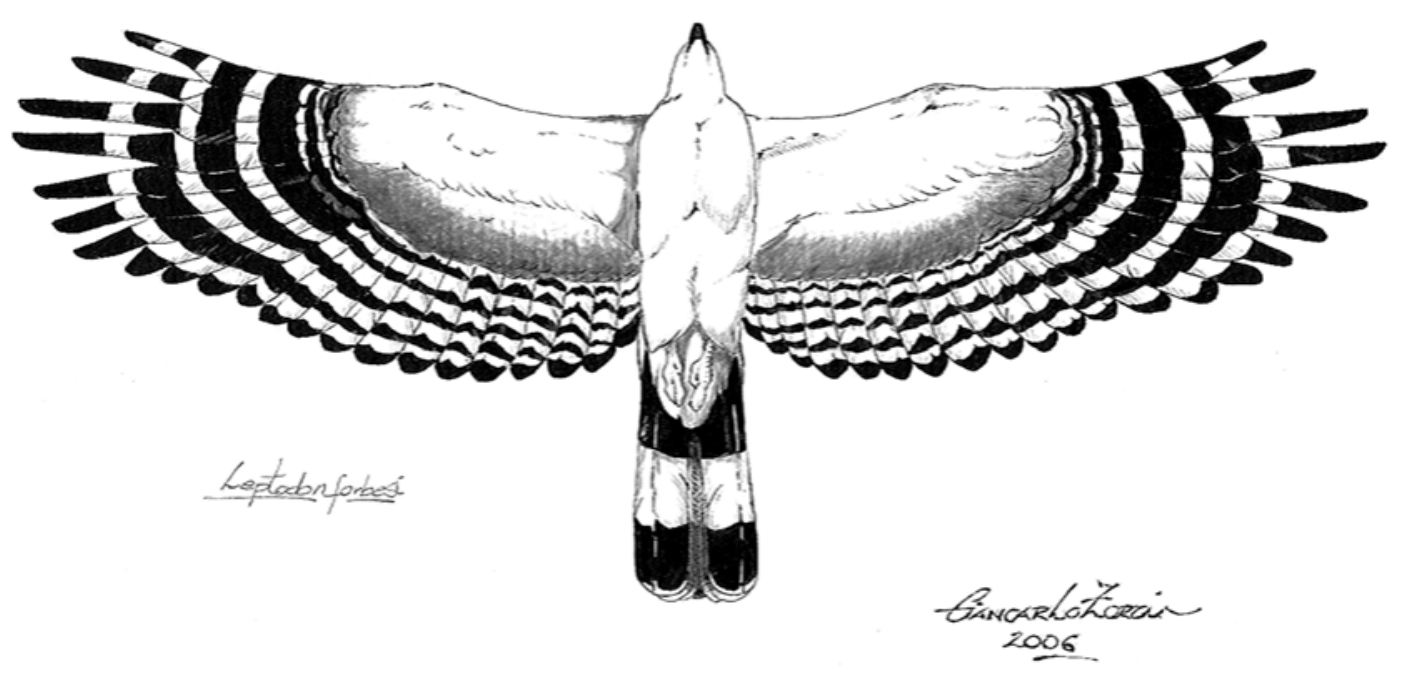

Figura 7. Vista das partes inferiores de Leptodon forbesi, em voo. Adaptado de Pereira et al. (2006). Ilustração (C) Giancarlo Zorzin. 


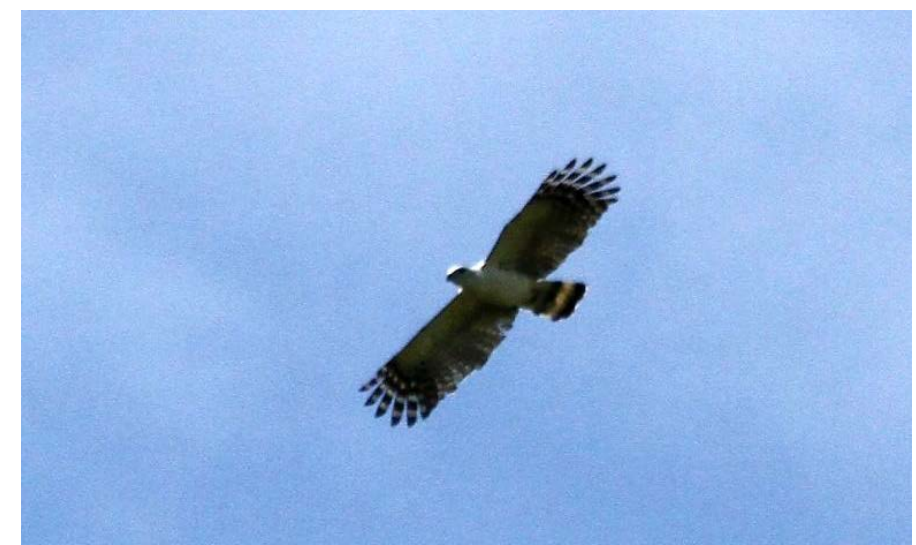

Figura 8. Vista das partes inferiores de Leptodon forbesi, em voo. RVS Mata do Buraquinho. Foto: Vicent K. Lo, 07/11/2013 (WA1154578).

Touit surdus (Kuhl, 1820)

Apuim-de-cauda-amarela

Golden-tailed parrotlet

Psittacidae de pequeno porte (comparativamente pouco maior que Forpus), com aproximadamente $15,2 \mathrm{~cm}$, de cor verde; fronte e loro castanho amarelado; penas escapulares castanho-bronzeadas (sépia); cauda curta, truncada (quadrada), com penas centrais verdes e laterais douradas nas bordas, com as pontas pretas no macho e verdes na fêmea (Meyer de Schauensee, 1970; Sick, 1985) (Figura 9).

Ocorre do nordeste ao sudeste do Brasil, na Paraíba (Conde, João Pessoa, Mamanguape, Rio Tinto, Santa Rita e Sapé); Pernambuco (Cabo de Santo Agostinho, Camargibe, Igarassu, Jaboatão dos Guararapes, Jaqueira, Lagoa dos Gatos, Moreno, Pau d'Alho, Paulista, Recife e Rio Formoso); Alagoas (Ibateguara, Maceió, Murici e Passo de Camaragibe); Sergipe (Estância e Santa Luzia do Itanhy), sudeste e sul da Bahia (Apuarema, Belmonte, Boa Nova, Cairu, Camacan, Camaçari, Entre Rios, Igrapiúna, Ilhéus, Itacaré, Jaguaquara, Jequié, Maragogipe, Porto Seguro e Santa Cruz de Cabrália); Espírito Santo (Afonso Cláudio, Alfredo Chaves, Aracruz, Cariacica, Conceição da Barra, Domingos Martins, Guarapari, Linhares, Santa Teresa, Sooretama e Vargem Alta) até o Rio de Janeiro (Cachoeiras de Macacu, Casimiro de Abreu, Guapimirim, Magé, Nova Friburgo, Nova Iguaçu, Petrópolis, Rio das Ostras, Silva Jardim e Teresópolis) (Meyer de Schauensee, 1970; Teixeira et al., 1995; Telino-Júnior et al., 2005; Magalhães et al., 2007; Almeida e Teixeira, 2010; RPPN Estação Veracel, 2016; IUCN, 2020; Wikiaves, 2020). No final do século XIX ocorria no baixo curso do Rio Tietê, em São Paulo (Sick, 1985, p. 309) e sem registros recentes para os brejos de altitude no Ceará e sul do Rio Grande do Norte (Wikiaves, 2020), provavelmente na RPPN Mata da Estrela.

Espécie rara, endêmica da Mata Atlântica, com alta sensibilidade aos distúrbios ambientais; habita ecossistemas florestais, como a Floresta Estacional Semidecidual das Terras Baixas (ver Brasil, 1981; Stotz et al., 1996), na Mata Atlântica no Nordeste do Brasil. Essa espécie está ameaçada pelo intenso desmatamento, necessitando de prioridade alta tanto para a conservação in situ, bem como pesquisas de campo (Stotz et al., 1996) e conservação ex situ, programa de criação em cativeiro, tendo em vista que é um psitacídeo pouco resistente em cativeiro (Pereira et al., 2014) e nunca tem sido visto no comércio ilegal de aves silvestres na Região Nordeste do Brasil ou raramente é capturado por comerciantes de aves (Teixeira et al., 1995, p. 16). Ainda não há registros de apreensões dessa espécie na Paraíba, quando se sabe que os psitacídeos (Psittacidae) estão entre os três grupos de aves mais frequentes em apreensões no Estado, representam cerca de 5\% das aves apreendidas entre os anos de 2006 e 2007 (Pagano et al., 2009, p. 134, 139). A espécie necessita urgente de pesquisas nas localidades históricas de ocorrência e do 
habitat adequado, com intensificação de trabalhos de campo para esclarecer a distribuição espacial atual, além de estudos sobre a autoecologia e movimentos sazonais (IUCN, 2020). Pois, qualquer tentativa de criação em cativeiro necessita de estudos sobre o habitat, hábitos alimentares, reprodução e potenciais impactos negativos e ameaças que afetam a espécie, os quais, virtualmente, irão garantir a eficácia de futuros trabalhos de reintrodução em áreas protegidas. Espécie contemplada no Plano de Ação Nacional (PAN) para Conservação das Aves da Mata Atlântica (Brasil, 2018b, p. 287; Brasil, 2018c).

Observou-se que T. surdus na RVS Mata do Buraquinho apresenta-se com frequência relativamente baixa (IFL $=0,060$ ), sensivelmente um pouco acima de L. forbesi. A maioria dos registros foi vocal, tendo sido visual uma única vez quando foi possível observar um grupo de seis indivíduos, na porção oeste da RVS (Po), em 02/08/2017, onde a vegetação encontra-se bem conservada (vegetação primária e/ou estágio avançado de regeneração, ver Barbosa, 1996; Brasil, 2007b), que se encontravam a uma altura de cerca de $10 \mathrm{~m}$ do solo, no interior da copa de uma árvore de grande porte (coordenadas UTM 293929.7069; 9209877.8456; zona 25M). Esse grupo observado apresentava-se silencioso e um dos indivíduos fazia busca com bicadas em um oco da árvore, ocupado por um pequeno cupinzeiro, deixando alguns fragmentos cair ao solo (Almeida, 2017a, b, c, d; Figura 9). Semelhante observação de uso de cupinzeiro foi registrada em Sapé, na RPPN Pacatuba (Pereira et al., 2014). Essas observações reforçam a dependência dessa espécie por de árvores de grande porte e velhas como fator limitante na manutenção das populações em florestas alteradas ou altamente degradadas em regeneração, as quais carecem de árvores com essas características (Pereira et al., 2014.).

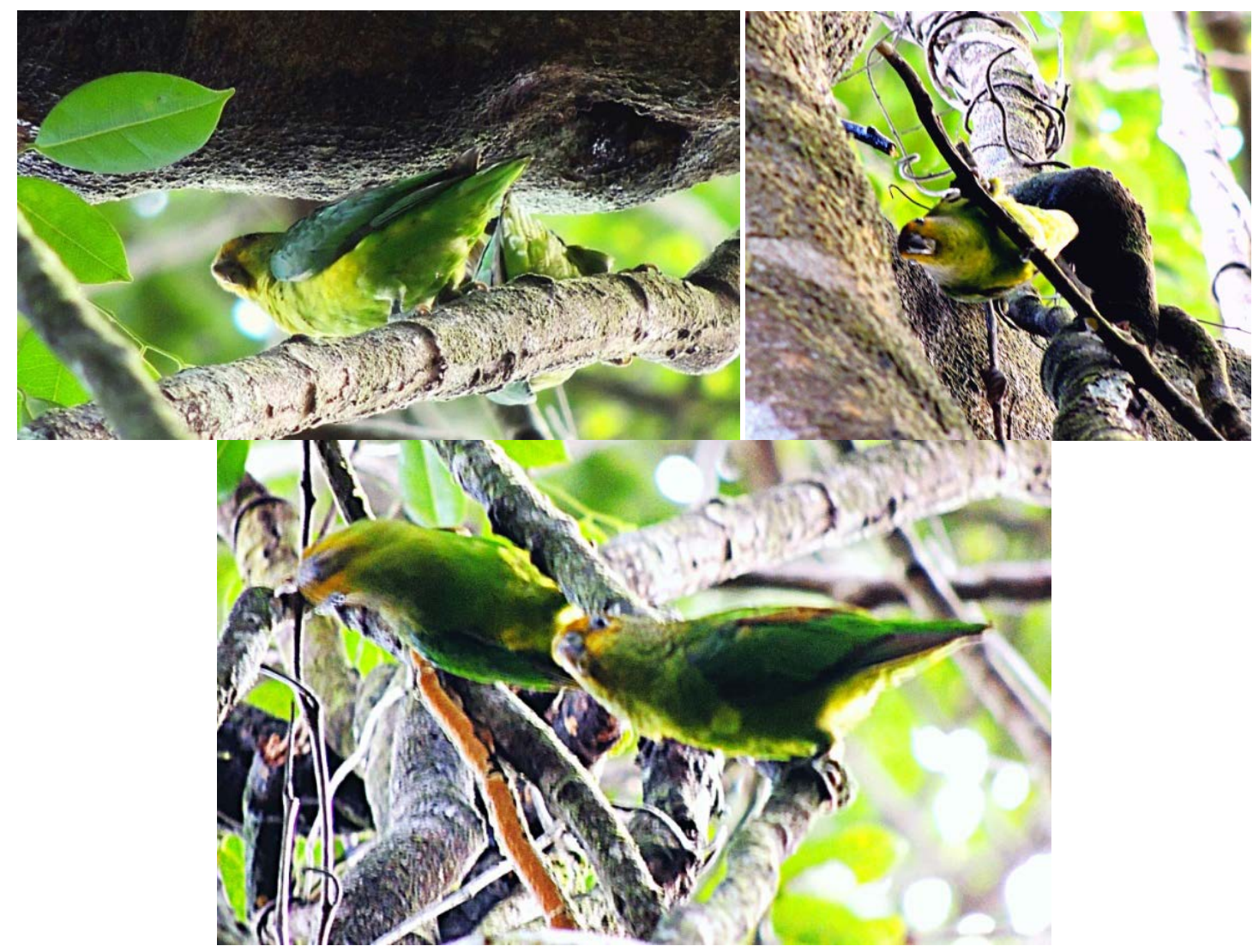

Figura 9. Grupo de Touit surdus a cerca de 10 metros de altura do solo, na floresta primária da RVS Mata do Buraquinho, 02/08/2017. Fotos: Cláudio Almeida (WA2646350, WA2646353, WA2646355). 
Xiphorhynchus atlanticus (Cory, 1916)

Sinonímia: Picolaptes fuscus atlanticus Cory, 1916; Lepidocolaptes fuscus atlanticus

(Cory, 1916); Xiphorhynchus fuscus atlanticus (Cory, 1916)

Arapaçu-rajado-do-nordeste

Northern lesser woodcreeper

Dendrocolaptidae com cerca de $18,5 \mathrm{~cm}$, que caracteriza-se pela tonalidade mais carregada do ocráceo das partes inferiores e na maior visibilidade da orla pardo escura das penas da garganta (Pinto e Camargo, 1961, p. 239) e por apresentar as penas infracaudais marrom ocre-avermelhadas (Meyer de Schauensee, 1970, p. 199; Grantsau, 2010, p. 622). Reconhecida e aceita como espécie independente por evidências morfológicas e genéticas, a qual foi separada do táxon subesepcífico de $X$. fuscus (X. f. atlanticus) (Cabanne et al., 2008, 2014).

Distribui-se no Nordeste de Brasil, no Ceará (Baturité, Graça, Guaraciaba do Norte, Guaramiranga, Meruoca, Mulungu, Pacoti, Tianguá, Ubajara); Paraíba (Mamanguape, Rio Tinto, João Pessoa, Pitimbu, Santa Rita); Pernambuco (Abreu e Lima, Belo Jardim, Bonito, Brejo da Madre de Deus, Jaqueira, Lagoa dos Gatos, Pau d'Alho, Paulista, Recife, Rio Formoso, São José da Coroa Grande, Tamandaré); Alagoas (Ibateguara, Murici, Quebrangulo) (Almeida e Teixeira, 2010; Brasil, 2018b; Wikiaves, 2020).

Espécie endêmica da Mata Atlântica do Nordeste do Brasil, no CEP, que possui alta sensibilidade aos distúrbios ambientais; relativamente frequente no habitat de ocorrência, onde habita florestas estacional semidecidual e montana (e.g. brejos de altitude) (Stotz et al., 1996); e a priori apresenta-se como uma espécie com alta prioridade para conservação e pesquisas, por encontrar-se no grupo das espécies endêmicas e ameaçadas (Pereira et al., 2016) com declínio populacional, perda continuada de área de distribuição espacial e da qualidade do habitat ao longo da área de ocorrência fragmentada (Brasil, 2018b) e parco conhecimento sobre sua história natural na região. Na avaliação global pela IUCN (2020) a espécie apresenta-se com o estado de conservação pouco preocupante (LC), porém aponta decréscimo na população.

No presente estudo essa espécie apresentou uma frequência relativamente alta (IFL $=0,250$ ), uma das mais altas entre os Passeriformes e a mais alta entre os táxons ameaçados registrados no estudo (ver Figura 6); possivelmente ocupa pequenos territórios e possui alta frequência e densidade, sendo assim, estudos demográficos (Ribon e Marini, 2016) podem auxiliar em planos para conservação dessa espécie, enquanto encontra-se na categoria "vulnerável". Espécie contemplada no Plano de Ação Nacional (PAN) para Conservação das Aves da Mata Atlântica e no Plano de Ação Nacional para a Conservação das Aves da Caatinga (Brasil, 2018b, p. 417; Brasil, 2018c).

Muito frequente em bandos mistos no sub-bosque, onde aparece ao lado de Xenops minutus alagoanus, Hemitriccus griseipectus naumburgae, Lanio cristatus, Picumnus pernambucensis e Veniliornis passerinus. Foi observado um indivíduo realizando a retirada de material lenhoso macio de um oco (e.g. V. passerinus) de uma árvore em adiantado estado de deterioração, a cerca de $6 \mathrm{~m}$ do solo, em provável atividade de nidificação (Almeida, 2017e, 2017f; 2017g; Figura 10). No presente estudo não foi registrada a ocorrência de outro Dendrocolaptidae, Dendroplex picus (Gmelin, 1788), frequentemente observado em bordas de mata (e.g. em vegetação alterada e jardins no entorno da RVS, no Bairro Varjão) e em áreas com vegetação secundária, alterada para agricultura de subsistência, a exemplo do que foi registrado na Bacia do Rio Gramame, no sul do Município de João Pessoa (Almeida, 2014a, 2014b, 2014c). 


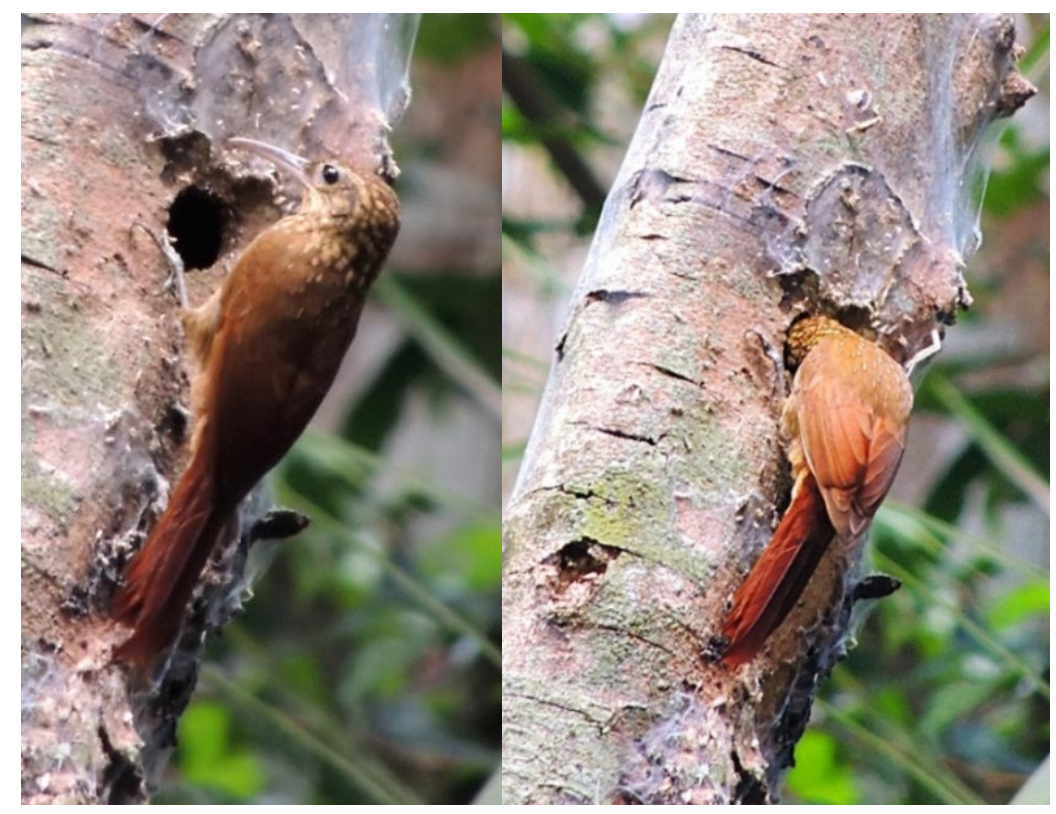

Figura 10. Xiphorhynchus atlanticus, em atividade de nidificação, a cerca de $6 \mathrm{~m}$ de altura do solo, no sub-bosque da floresta. RVS Mata do Buraquinho, 06/10/2017. Fotos: Cláudio Almeida (WA2763754, WA3973109).

\section{Xenops minutus alagoanus Pinto, 1954 \\ Bico-virado-miúdo \\ Plain xenops}

Esta subespécie de Xenopidae (Tyranni, Furnariides, Piacentini et al., 2015, p. 168, 195) de aproximadamente $12,7 \mathrm{~cm}$ é algo semelhante à subespécie $X$. m. genibarbis Illiger, 1811, de mais ampla distribuição no Brasil (Rio Madeira até o norte do Maranhão, Piauí e para o sul, até o Mato Grosso do Sul e norte de Goiás) (Pinto, 1954; Grantsau, 2010), por apresentar coloração da plumagem mais clara, "parda arruivada", com as coberteiras das asas marrom-avermelhadas; no alto da cabeça, ausência de estriações no píleo e mento indistintamento estriado (Pinto, 1954, p. 46-47; Pinto, 1978, p. 335; Grantsau, 2010, p. 645).

Distribui-se do Rio Grande do Norte (Baía Formosa, Canguaretama, Espírito Santo), Paraíba (Areia, Cabedelo, Conde, João Pessoa, Mamanguape, Rio Tinto, Santa Rita, Sapé), Pernambuco (Bonito, Cabo de Santo Agostinho, Catende, Gameleira, Jaqueira, Lagoa dos Gatos, Pau d'Alho, Paulista, Recife, Rio Formoso, São José da Coroa Grande), Alagoas (Coruripe, Maceió, Murici, Pilar, Rio Largo, São Miguel) (Pinto, 1954; Almeida e Teixeira, 2010; Brasil, 2018b; Wikiaves, 2020).

Cabe notar que Pinto (1954, p. 47), refere-se a exemplares do Maranhão (Miritiba), que apresentam provável transição entre $X$. m. genibarbis e Xenops m. alagoanus; e ainda cita a forma nominal Xenops m. minutus (Sparrman, 1788), de distribuição mais meridional, da Bahia a Santa Catarina. Sendo assim, o complexo Xenops minutus necessita de investigação sobre a vocalização, morfologia e genética (ver Piacentini et al., 2015, p. 195), no sentido de estabelecer limites da real destruição da subespécie Xenops minutus alagoanus, a qual pode figurar virtualmente como espécie plena, independente, seguindo possível "modelo biogeográfico" de distribuição e evolução similar a Xiphorhynchus atlanticus no nordeste do Brasil. Os tratamentos dados aos táxons como espécies ou subespécies refletem estudos taxonômicos desiguais para as aves da região Nordeste do Brasil (Barnett e Buzzetti, 2014, p. 89), tal como exemplo a espécie anterior. 
Táxon com "média" sensibilidade aos distúrbios ambientais é relativamente comum nas florestas de terras baixas, na Mata Atlântica (Stotz et al., 1996). Requer alta prioridade para conservação e pesquisas, pela dependência de florestas, nas quais se mostra ausente em fragmentos pequenos e carece de estudos sobre morfologia, genética e história natural, tendo em vista que a população está severamente fragmentada e há declínio continuado de qualidade do habitat. Táxon contemplado no Plano de Ação Nacional (PAN) para Conservação das Aves da Mata Atlântica e no Plano de Ação Nacional para a Conservação das Aves da Caatinga (Brasil, 2018b, p. 449; Brasil, 2018c).

Muito frequente em bandos mistos no sub-bosque, ao lado de Xiphorhynchus atlanticus, Hemitriccus griseipectus naumburgae, Lanio cristatus, Picumnus pernambucensis, Veniliornis passerinus (Almeida, 2018a, b, c). Apresentou a segunda frequência mais alta (IFL $=0,202$ ), entre os táxons ameaçados registrados no estudo (Figura 11).

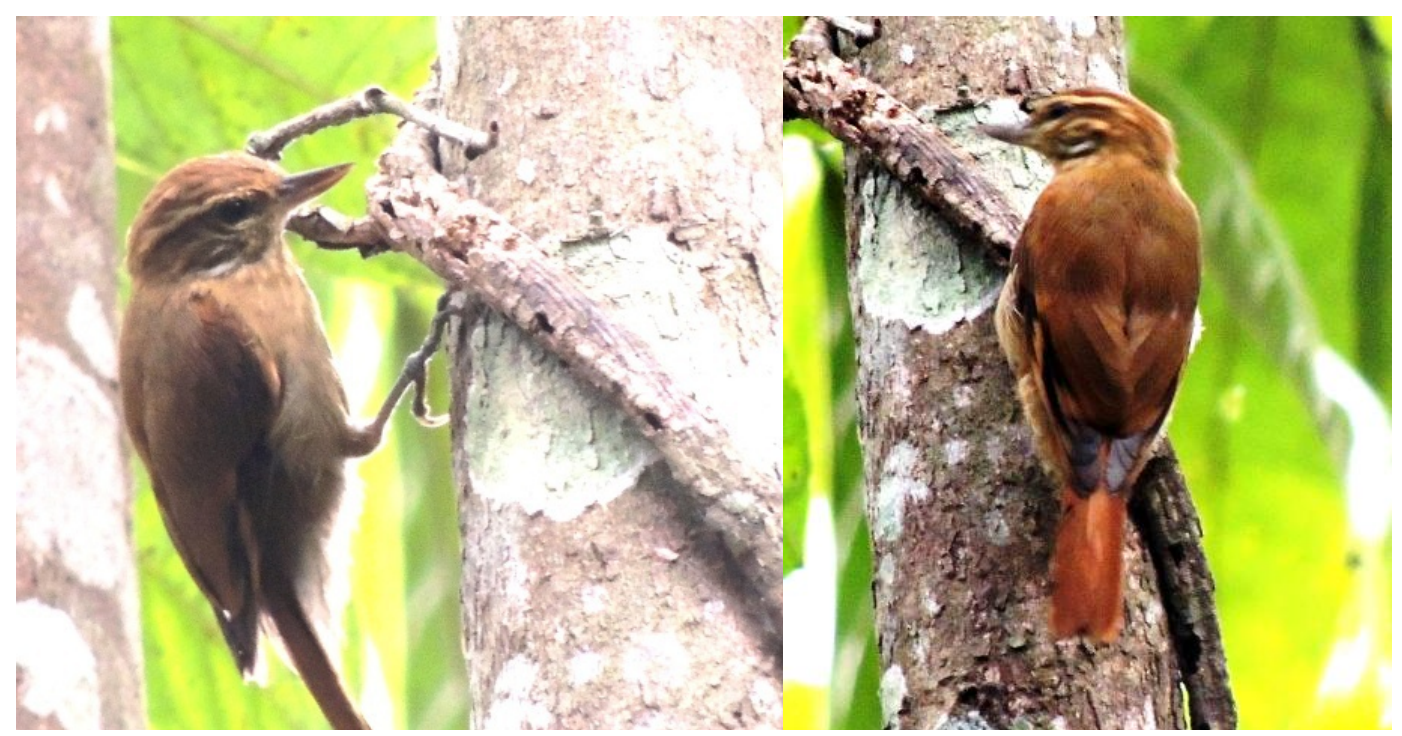

Figura 11. Xenops minutus alagoanus, forrageando em bando misto no sub-bosque da floresta, a cerca de 3 metros do solo. RVS Mata do Buraquinho, 13/01/2018. Fotos: Cláudio Almeida (WA2866183; WA2871601).

Iodopleura pipra leucopygia Salvin, 1885

Anambezinho

Buff-throated purpletuft (Salvin's purpletuft)

Esse pequeno Tityridae (e.g. Cotingidae, ver Snow, 1982), com cerca de $10 \mathrm{~cm}$ de comprimento, apresenta o dorso cinza e uma banda branca supracaudal ("rump") (Salvin, 1885, p. 305) e faixa superciliar contrastante, o que o distingue de I.p. pipra (Lesson, 1831). Peito superior, garganta e coberteiras inferiores da cauda ocre rosado intenso; tufos peitorais roxos nos machos e ausentes nas fêmeas; restante da parte inferior branca, com barras pretas (Meyer de Schauensee, 1970, p. 268; Teixeira et al., 1993, p. 51; Grantsau, 2010, p. 700) (Figura 12).

Essa subespécie está distribuída no nordeste do Brasil, no CEP, da Paraíba (Mamanguape, Rio Tinto, João Pessoa), Pernambuco (Camaragibe, Garanhuns, Gravatá, Jaqueira, Recife, São Benedito do Sul), Alagoas (Maragogi, Murici, São José da Laje, São Miguel dos Milagres), até a Bahia (Boa Nova, Camacan, Ibirapitanga, Ibirataia, Iguaí, Ipiaú, 
Jequié, Poções) (Teixeira et al., 1993; Almeida e Teixeira, 2010; Almeida, 2016a; 2016b; 2017h; 2017i; 2018d; 2018e; Fukusima, 2019; Wikiaves, 2020).

Esse táxon foi redescoberto no nordeste do Brasil em 1989, conforme descreve Teixeira et al. (1993, p. 51):

Descrita em 1885, a Iodopleura pipra leucopygia é baseada em dois machos de origem desconhecida. Conforme mencionado por Snow (1982), esses espécimes (BMNH 88120969, 88120970) foram obtidos por Salvin de H. Whitely, um conhecido negociante de material de história natural de Londres, e foram considerados provenientes da Guiana Britânica; mas Snow sugeriu a possibilidade de que eles pudessem ter vindo de algum lugar do nordeste do Brasil. Durante os últimos anos, constatamos que este cotingídeo habita a Mata Atlântica do Nordeste do Brasil, de onde obtivemos uma fêmea adulta (MN 36379, gônadas 5 mm, 10,5 g, 105 mm de comprimento total) e um macho adulto (MN 36380, gônadas 2 mm, 9,6 g, $101 \mathrm{~mm}$ de comprimento total) de Mamanguape, litoral da Paraíba (c. $6^{\circ} 50^{\prime} \mathrm{S}, 35^{\circ} 07^{\prime} \mathrm{W}$ ) em maio de 1989 . Também pode ser observado que o USNM abriga uma quinta pele (USNM 536504), uma fêmea adulta com base na plumagem, coletada por W. L. Ellison, em Garanhuns, Pernambuco (c. $8^{\circ} 54^{\prime} \mathrm{S}, 36^{\circ} 29^{\prime} \mathrm{W}$ ) em julho de 1957 . Este material está em estudo, e ressaltamos que I. pipra leucopygia difere consideravelmente da forma nominal da espécie pela larga faixa branca no uropígio, faixa superciliar contrastante e as partes inferiores extensamente esbranquiçadas.

Táxon com "média" sensibilidade aos distúrbios ambientais nas florestas de terras baixas, na Mata Atlântica, onde é endêmico (Stotz et al., 1996), pouco comum, sendo muito raro ao longo da sua área de distribuição irregular (restrita à Mata Atlântica no Nordeste do Brasil, acima do Rio São Francisco). Pela raridade na sua área de distribuição e perda de habitat, tornam-se urgentes esforços para conservação e pesquisas, a fim de garantir a persistência desse táxon no CEP. Diante da inexistência de estudos moleculares e genéticos, qualquer esforço nesse sentido tende a remeter a um provável reconhecimento desse táxon como uma espécie independente - Iodopleura leucopygia, que seria plenamente diagnosticável, do ponto de vista taxonômico. Cabe ressaltar que Barnett e Buzzetti (2014, p. 89), apontam que para esses táxons os tratamentos como espécies ou subespécies refletem estudos taxonômicos desiguais para as aves da Região Nordeste do Brasil.

A população encontra-se em declínio continuado devido à sua fragmentação e à perda de habitat pelo desmatamento, estando criticamente ameaçada de extinção. Táxon contemplado no Plano de Ação Nacional (PAN) para Conservação das Aves da Mata Atlântica (Brasil, 2018b, p. 496).

Frequenta as clareiras, bordas da floresta e áreas com arborização urbana (e.g. bordas da RVS e Campus I da UFPB), juntamente com Euphonia chlorotica, esta espécie tem sido observada forrageando em ervas-de-passarinho ("mistletoes" /"bird's herb grass") [e.g. Passovia pyrifolia (Kunth) Tiegh.; Fam. Loranthaceae; NYBG 1874673 (JPB 51.903)], como já havia sido registrado por Teixeira et al. (1993, p. 51), sendo essa uma indicação relevante da ecologia da espécie, até então pouco conhecida, o que facilita a sua busca em estudos de história natural e censo. Tendo em vista as semelhanças da ecologia comportamental com E. chlorotica, característica essa que provavelmente a deixou despercebida em levantamentos de campo durante muitas décadas. Não obstante até mesmo dada como possivelmente extinta na Guiana (Hume, 2017, p. 506), onde provavelmente nunca ocorreu. Tendo em vista a dificuldade de detecção, atestado em todos os avistamentos realizados, nos quais se encontravanas topo das copas das árvores e quando ao lado de E. chlorotica vocalizando, pode ser confundida com a mesma pela grande semelhança vocal entre elas. A voz (canto/"song") consiste em duas notas, a primeira ascendente que estabiliza na porção média e outra curta levemente ascendente. Numa aproximação da transcrição da voz seria como "siûí... siûí (sí... sî)" (Almeida, 2018d;

Rev. Bras. Gest. Amb. Sustent., 2021, vol. 8, n. 18, p. 37-75. 
2018e; Figura 13), bastante similar a "fim..fim", de Euphonia chlorotica; também são emitidos chamados com uma nota (vide Almeida, 2016a; 2016b; 2017h; 2017i), sendo que a última espécie apresenta a frequência um pouco mais baixa $(<5 \mathrm{kHz}$ ) (Figura 14; Pereira, 2006).

Cabe notar que I. pipra leucopygia foi observada regurgitando as sementes da erva-de-passarinho, e como esses frutos possuem uma mucilagem viscosa, os indivíduos sempre passam o bico nos galhos para se livrar das sementes, enquanto E. chlorotica defeca as sementes em pequenos "colares", a qual esfrega a cloaca nos galhos. Possivelmente essas estratégias favorecem a dispersão e reinfestação da erva-de-passarinho nas copas das árvores, particularmente nas "castanholas" ("amandoeira"; "indian almond"; "chestnut tree"; EAC 25.245; ASE 12.098; NYBG 565726) (Terminalia catappa L.; Família Combretaceae) naturalizadas; a qual tem demonstrado ser uma ótima espécie hospedeira da hemiparasita Passovia pyrifolia, no Campus I da UFPB (João Pessoa) e no entorno da RVS Mata do Buraquinho.

Na RVS Mata do Buraquinho I. p. leucopygia apresentou a segunda mais baixa frequência entre os táxons ameaçados (IFL $=0,060$ ) registrados e um dos mais baixos entre os passeriformes, o que demanda mais esforços de campo e estratégias específicas para busca e detecção dessa espécie na área, a fim de auxiliar na elaboração de um plano local para a conservação desse táxon.

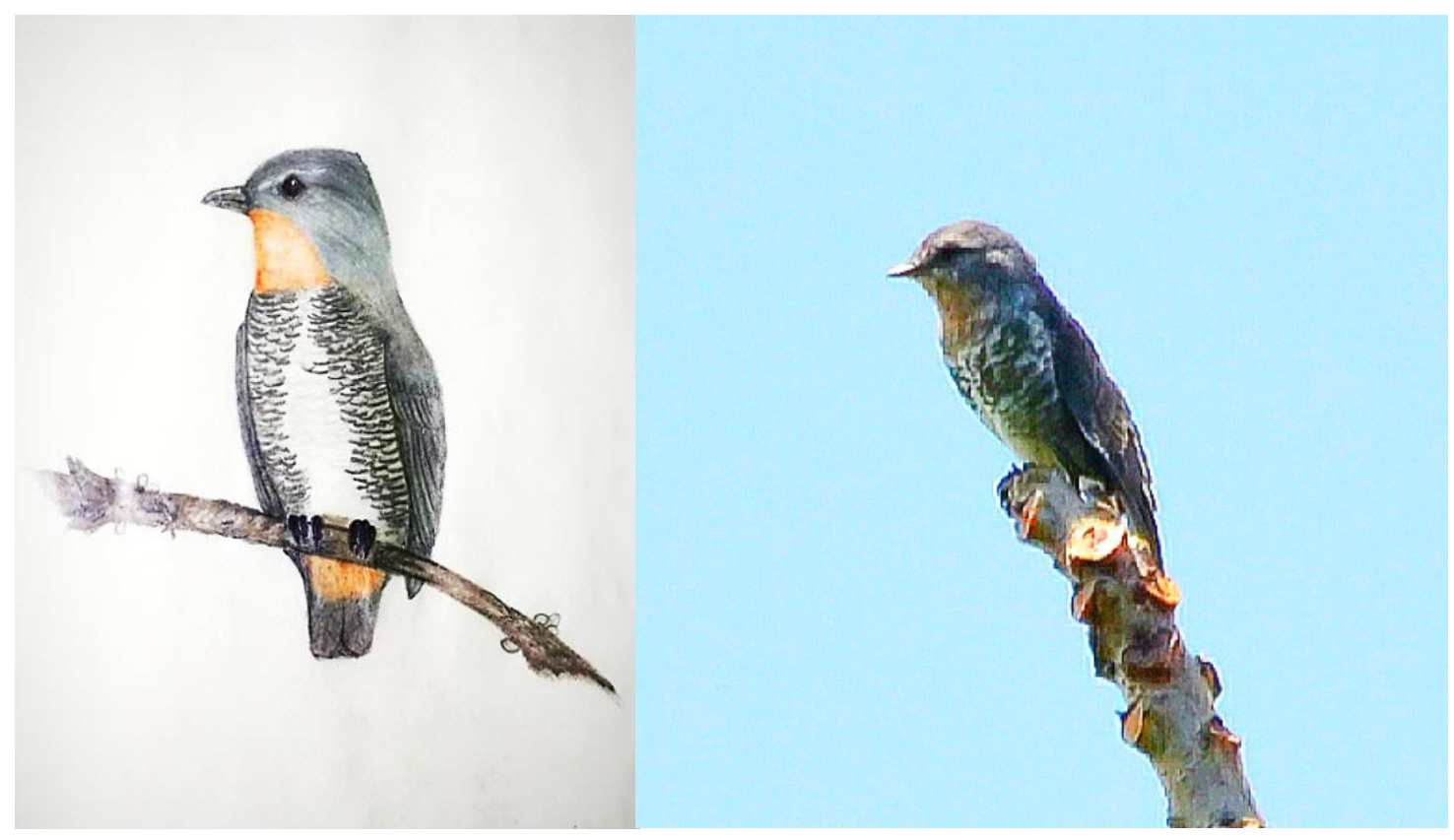

Figura 12. Iodopleura pipra leucopygia. À esquerda, esboço a partir de caderneta de campo, Campus I da UFPB (João Pessoa), Cláudio Almeida, 30/03/1995. À direita, foto de Sérgio Fukusima, RVS Mata do Buraquinho, 22/10/2019 (WA3652503).

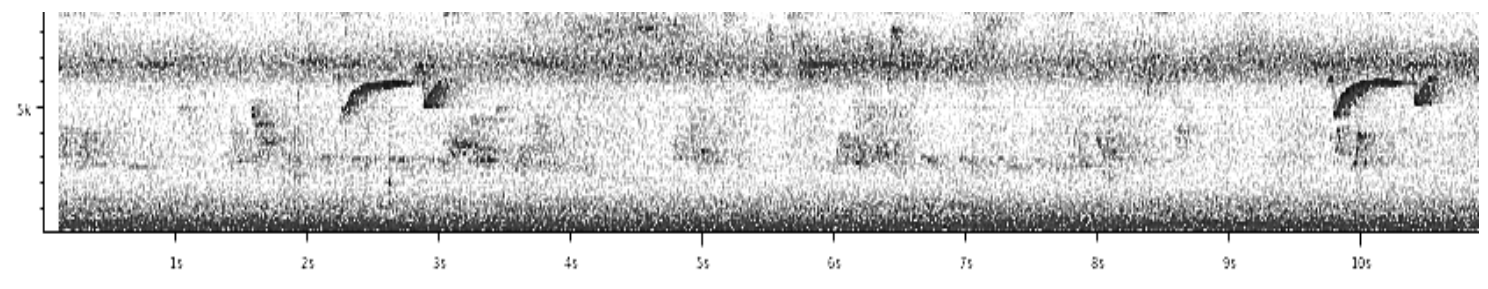

Figura 13. Sonograma da vocalização (canto) Iodopleura pipra leucopygia, RVS Mata do Buraquinho, 28/01/2018 (Almeida, 2018e; XC401291). 


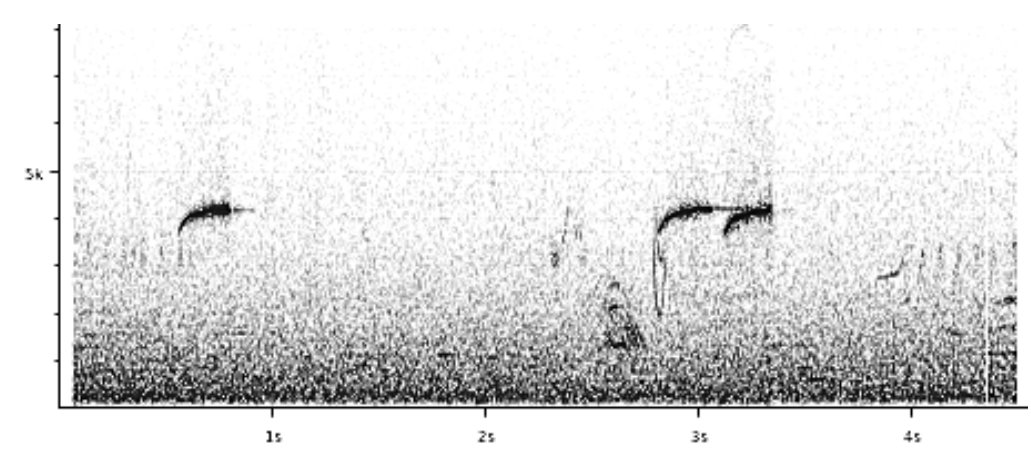

Figura 14. Sonograma da vocalização (canto) de Euphonia chlorotica, Altinho, Pernambuco, (Pereira, 2006; XC7540).

\author{
Hemitriccus griseipectus naumburgae (Zimmer, 1945) \\ Sinonímia: Idioptilon zosterops naumburgae (Zimmer, 1945); \\ Euscarthmornis zosterops naumburgae Zimmer, 1945. Proc. Biol. Soc. \\ Wash., LVIII: 45. \\ Maria-de-barriga-branca \\ White-bellied tody-tyrant
}

Esse Rhynchocyclidae florestal de cerca de $11 \mathrm{~cm}$, distingue-se da subespécie amazônica, H. g. griseipectus (Snethlage, 1907), pelo verde oliváceo mais claro do dorso, penas do píleo distintamente escurecidas na porção central, pela grande mistura de verde oliváceo no cinzento do peito, estriação mais intensa da garganta, flancos ligeiramente esverdeados e pela maior largura e colorido mais escuro do bico (Pinto, 1954, p. 74) (Figura 15).

Exclusiva do Centro de Endemismo de Peranambuco (CEP), esta ave distribui-se do Rio Grande do Norte (Baía Formosa, Canguaretama, Goianinha, Natal), Paraíba (Cruz do Espírito Santo, João Pessoa, Mamanguape, Rio Tinto, Santa Rita, Sapé), Pernambuco (Abreu e Lima, Água Preta, Camaragibe, Catende, Gameleira, Jaqueira, Lagoa dos Gatos, Pau d'Alho, Paulista, Recife, Rio Formoso, São José da Coroa Grande, Tamandaré, Xexéu), Alagoas (Atalaia, Barra de São Miguel, Campo Alegre, Maragogi, Murici, Passo de Camaragibe, Pilar, São Miguel dos Milagres) (Almeida e Teixeira, 2010; Almeida, 2017j, 2017k, 2017l, 2017m, 2017n; Wikiaves, 2020).

Táxon com "média" sensibilidade aos distúrbios ambientais, relativamente frequente ou comum (Stotz et al., 1996, p. 230), nos ecossistemas de Florestas Estacionais de terras baixas no Nordeste do Brasil. A população está bastante fragmentada e há declínio continuado de habitat (Brasil, 2018b, p. 526). Carece de estudos sobre a sua história natural e densidade poluacional. Sendo esse táxon mais um prioritário para estudos moleculares e genéticos, considerando-se o padrão de distribuição geográfica (restrita à Mata Atlântica acima do Rio São Francisco), o que seria favorável considerar como uma espécie plena, Hemitriccus naumburgae. Considerando que a observação de Barnett e Buzzetti (2014, p. 89), aponta que para esses táxons os tratamentos como espécies ou subespécies refletem estudos taxonômicos desiguais para as aves da Região Nordeste do Brasil. As características da vocalização também apontam como uma subespécie de H. naumburgae (Brasil, 2018b, p. 526).

As aves do gênero Hemitriccus são pequenas, territorialistas, monogâmicas, não migratórias, dependentes de florestas e sem boa capacidade para dispersão (Cohn-Haft 2000), o que torna algumas espécies suscetíveis à extirpação, em decorrência das mudanças climáticas por perda de áreas adequadas à sobrevivência, particularmente em estudos realizados no Bioma Mata Atlântica (Souza, 2017). Tentativamente podem ser considerados potenciais bioindicadores ambientais.

Rev. Bras. Gest. Amb. Sustent., 2021, vol. 8, n. 18, p. 37-75. 
No presente estudo, Hemitriccus griseipectus naumburgae (IFL $=0,190$ ), apresentou-se relativamente frequente no sub-bosque (médio), onde tem sido registrado quase sempre solitário (Figura 15), muito raramente observado nas copas das árvores e com relativamente frequente em bandos mistos. Os territórios encontravam-se distribuídos em diversos sítios da área de estudo, porém relativamente próximos ao longo das trilhas percorridas, tendo em vista que para esse táxon de história natural desconhecida, seria oportuno o desenvolvimento de estudos ecológicos, a fim de avaliar a densidade populacional e outros aspectos da biologia dessa ave; cabendo notar que estudos revelaram que algumas espécies da Mata Atlântica apresentam pequenos territórios e alta densidade (Ribon e Marini, 2016), o que provavelmente, remete à possibilidade de populações submetidas a contínuo processo de perda de habitat e fragmentação florestal desenvolvam essa capacidade adaptativa.

H. g. naumburgae está contemplado no Plano de Ação Nacional (PAN) para Conservação das Aves da Mata Atlântica (Brasil, 2018b, p. 527).

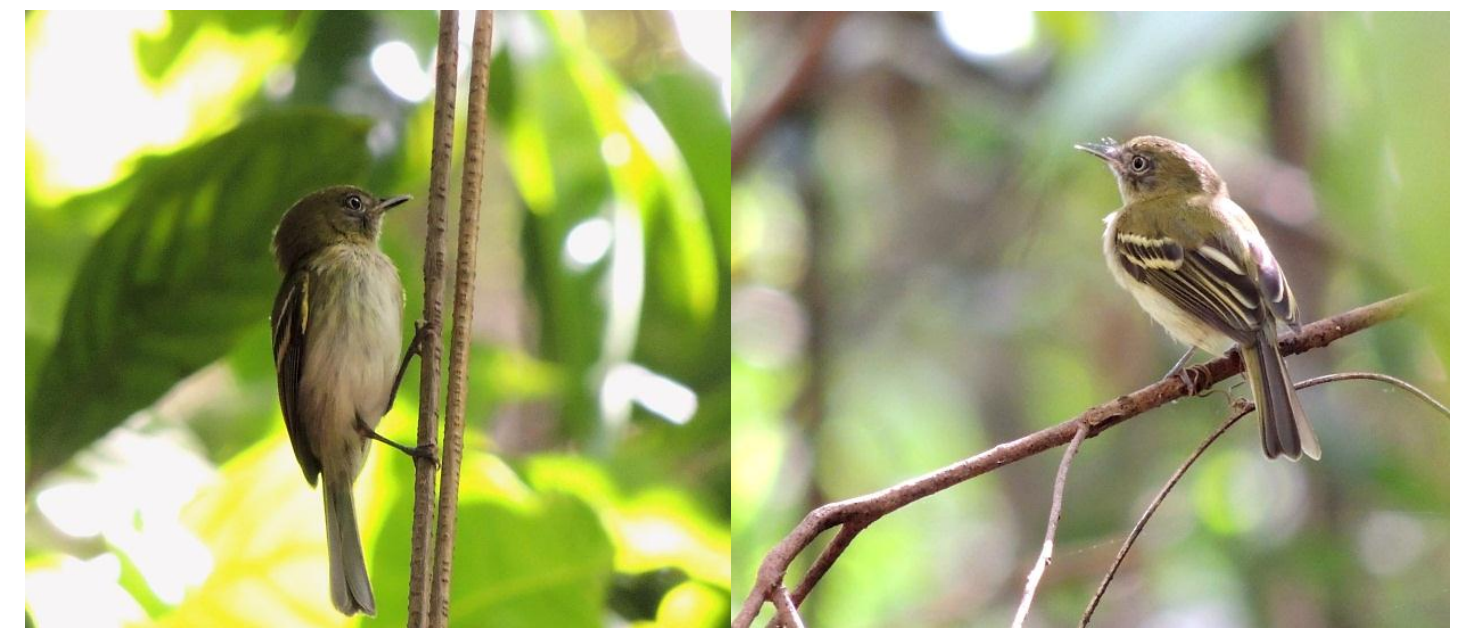

Figura 15. Hemitriccus griseipectus naumburgae, no sub-bosque da RVS Mata do Buraquinho, 07/10/2017; 31/12/2017. Fotos: Cláudio Almeida (WA2727938, WA2833399).

Cabe ressaltar as ausências de registros nas amostragens ( $n=84)$ na RVS Mata do Buraquinho das espécies Trogon curucui Linnaeus, 1766, Myiothlypis flaveola Baird, 1865, Manacus manacus (Linnaeus, 1766), Poecilotriccus fumifrons (Hartlaub, 1853) (Almeida, 2017o, 2017p, 2017q, 2017r) e Conopophaga cearae (MN 43.276; 05/05/1995) [em perigo de extinção - EN, B2ab(ii,iii), Brasil, 2018b, p. 369], encontradas na mata ciliar do Rio Cabelo (coordenadas UTM 299489.4456; 9207307.7480; zona 25M), na zona sudeste do Município de João Pessoa, em ecótono [Floresta Estacional Semidecidual e Savana ("cerrado"), ver Brasil, 1981], com marcante efeito de borda e desmatamento. Essas ausências provavelmente refletem o efeito da fragmentação florestal com o isolamento dos fragmentos sem conectividade e perda de habitats adequados para a persistência das referidas espécies. Entretanto, novos estudos serão necessários, a fim de realizar buscas com maior esforço de campo em áreas mais isoladas da RVS não acessadas no presente estudo.

Em estudo de avaliação dos tamanhos de nove reservas florestais da Região Metropolitana de João Pessoa (PB) e a riqueza de espécies de suas aves, nas quais incluiu também a unidade de conservação onde o presente estudo foi realizado, Enedino et al. (2018) afirmam que "os resultados destacam que as reservas urbanas de qualquer tamanho são valiosas para a conservação de aves em regiões metropolitanas, embora as maiores sejam priorizadas". Partindo dessa constatação, cabe citar Marsden et al. (2005), os quais destacam que quando se desconhece os tamanhos das populações mínimas 
viáveis (MVP "minimum populations viable") para as espécies registradas e ainda se o tamanho das áreas são iguais ou inferiores a 1.000 ha, como área favorável à manutenção de populações viáveis, supõe-se que qualquer tamanho de área, provavelmente, não seja suficiente para preservar muitas espécies, particularmente as endêmicas dependentes de florestas e ameaçadas de extinção. Assim, medidas urgentes são necessárias para reconectar esses remanescentes florestais ("pequenos" e isolados), a fim de garantir uma maior área de cobertura florestal propícia e assim permitir um fluxo gênico entre essas populações, caso contrário, teremos a otimização das "extinções locais" (Marsden et al., 2005) ou microextinções (ou extirpações, Souza, 2017, p. 33).

Sendo assim, a área de 512,93 ha do Refúgio de Vida Silvestre Mata do Buraquinho será suficientemente funcional, em médio e longo prazo, para a conservação das espécies endêmicas ameaçadas de extinção, num cenário de mudanças climáticas ou crise ambiental? Pois, a área tem uma comunidade de aves, composta por muitas espécies dependentes de floresta e o refúgio encontra-se isolado na malha urbana da cidade, sem conexões com outros remanescentes florestais menores. Então, baseado nessas informações torna-se necessária à elaboração de um plano de manejo que contemple todas essas questões, no sentido de garantir a persistência da avifauna (e fauna) florestal na unidade de conservação; incluindo as diferentes esferas de governanças locais responsáveis pela gerência e ações supletivas no território de influência direta da RVS e políticas públicas destinadas à conservação (criação e manutenção) de áreas protegidas e criação de corredores ecológicos.

Os principais impactos ambientais negativos observados, que potencialmente afetam o ecossistema florestal que mantém a comunidade de aves na RVS Mata do Buraquinho, foram: (a) coleta e corte seletivo de plantas observado na porção nordeste do refúgio, na trilha Bambuzal (Figura 16); (b) poluição hídrica ao longo de todo corpo hídrico é possível avaliar qualitativamente (Resolução CONAMA no 357/2005, Brasil, 2005), a percepção de odor característico de esgoto e/ou águas servidas, cor alterada e presença de espumas não naturais nas águas do Rio Jaguaribe que atravessa a unidade de conservação (Figura 16); (c) pesca, amiúde são encontrados petrechos de pesca com linha no interior da unidade de conservação (Figura 16); (d) caça, em "espera", possivelmente para tatu-verdadeiro, Dasypus novemcinctus, Linnaeus, 1758 (coodenadas UTM 295393.4816; 9209417.8233; zona 25M); observada na borda do ecótono do Pse, nas proximidades com a BR 230 (Figura 17) e com armadilha tipo "ratoeira" (coodenadas UTM 293453.9517; 9210406.5065; 25M), no entorno com a comunidade no bairro Varjão (Figura 17); (e) queimadas nas bordas, ao longo da BR 230; (f) poluição sonora e pisoteamento, na utilização das trilhas para visitação sem definição de capacidade de carga; (g) (re)introdução de espécies da fauna nativa (nativas alóctones), sem estudos ou projeto de translocação, a exemplo da observação de dois primatas, um adulto e jovem de Sapajus flavius (Schreber, 1774) (coodenadas UTM 293438.6217; 9210330.9727; zona $25 \mathrm{M})$ no interior da floresta, circulando nas copas das árvores e um indívíduo adulto de Alouatta belzebul (Linnaeus, 1766) (coodenadas UTM 293509.00; 9210947.00; zona 25M), localizado na borda, alimentando-se em árvores altas [e.g. Handroanthus impetiginosus (Mart. ex DC.) Mattos] (Figura 18), limítrofe à área urbana (Bairro Jaguaribe). Apesar da primeira espécie já ter sido registrada como "reintroduzida" por Fialho et al. (2014), nenhuma outra informação está disponível sobre estudos prévios de (re)introdução ou translocação; quanto à segunda espécie nenhuma informação está disponível na literatura ou em projeto de translocação e (re)introdução pelo Centro de Primatologia do Brasil (CPB) para essa unidade de conservação, execeto para a Rebio Guaribas (Souza, 2005 e com. pess., 2020). Alguns desses impactos ambientais são particularmente frequentes no entorno e/ou bordas da floresta, como nas vias de acesso (e.g. BR 230) e nas faixas de contato com as comunidades humanas do entorno (e.g. Comunidades Monte Cassino e São Geraldo), na zona oeste, limites com os bairros Jaguaribe, Varjão e Cristo Redentor. Tais impactos denotam uma ausência e/ou ineficiência de fiscalização efetiva na unidade de conservação. Enquanto outros impactos, tais como poluição sonora (circulação de veículos 
no entorno e da visitação sem definição de capacidade de carga das trilhas); poluição hídrica e (re)introdução de fauna são dependentes da normatização, medidas de mitigação/cessação e manejo de fauna são aspectos a serem estabalecidos em plano de manejo da unidade de conservação, a qual ainda não disponhe de tal instrumento de gestão. Quanto às (re)introduções de primatas na unidade de conservação, cabe notar que projetos de refaunação ("rewilding"; medidas estratégicas de reintrodução de espécies nativas localmente extintas, visando a reverter as extinções locais e a restaurar processos ecológicos e serviços ecossistêmicos) o maior problema não somente a possibilidade de falhar em restaurar as interações perdidas, mas o risco de obter novas interações indesejadas, quando as espécies adquirem uma gama de novos papéis ecológicos imprevisíveis quando introduzidas, muitas vezes levando às populações nativas e comunidades a destinos trágicos, podendo tornarem-se pragas (Oliveira-Santos e Fernandez, 2010), provocando intenso pisoteio e eliminação de vegetação herbácea limícola, a exemplo das capivaras (Hydrochoerus hydrochaeris Linnaeus, 1766), que frequentam as margens do Rio Jaguaribe (Figura 18) e predadores de ninhos de aves, tal como os macacos-prego (ver Rodrigues, 2013, p. 33). Se os planos de refaunação, para quaisquer grupos animais, ignorarem esses aspectos, o risco de extinguir e reduzir irreversivelmente as populações nativas de muitas espécies será alto (Oliveira-Santos e Fernandez, 2010, p. 4).

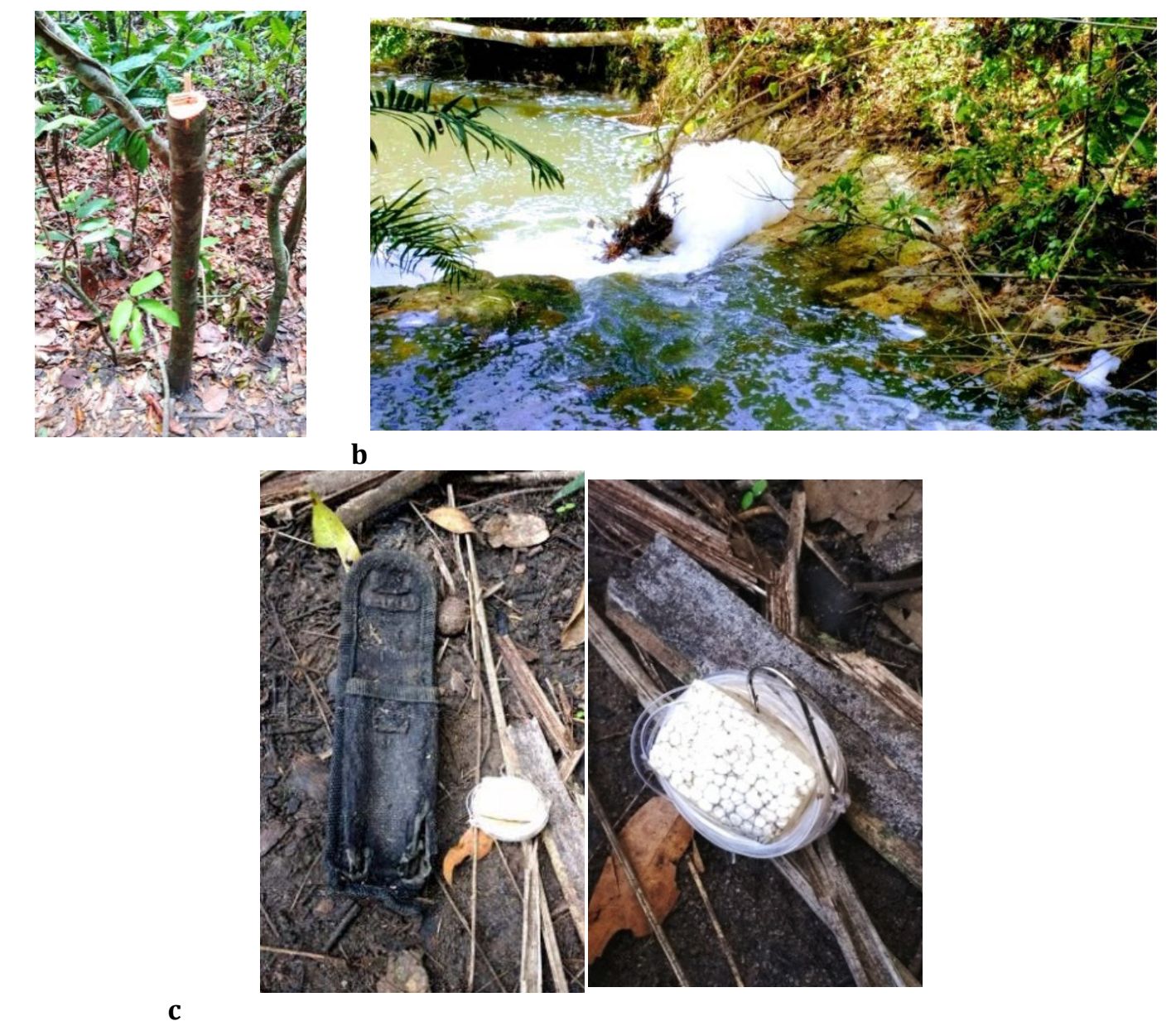

Figura 16. Corte seletivo de plantas (arbóreas), no sub-bosque (a); poluição hídrica (b); petrechos de pesca (c) na RVS Mata do Buraquinho, 12/11/2016, 02/08/2017, 13/08/2017. Fotos: Cláudio Almeida. 


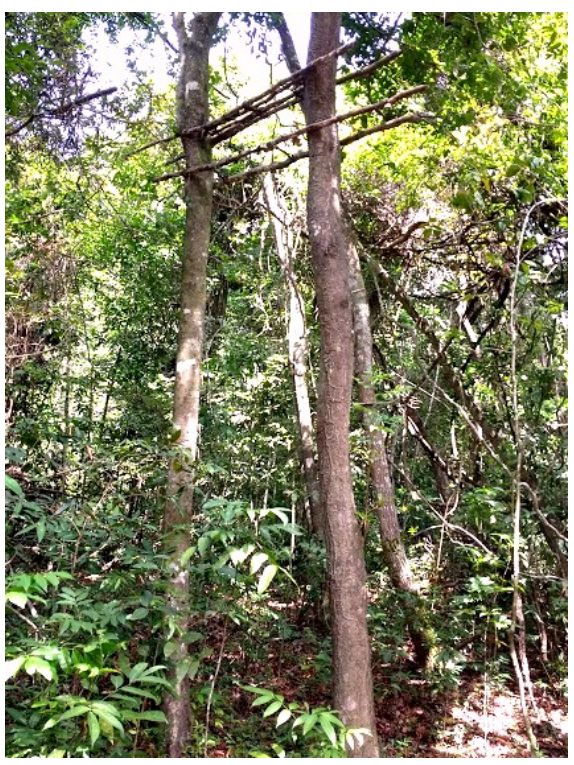

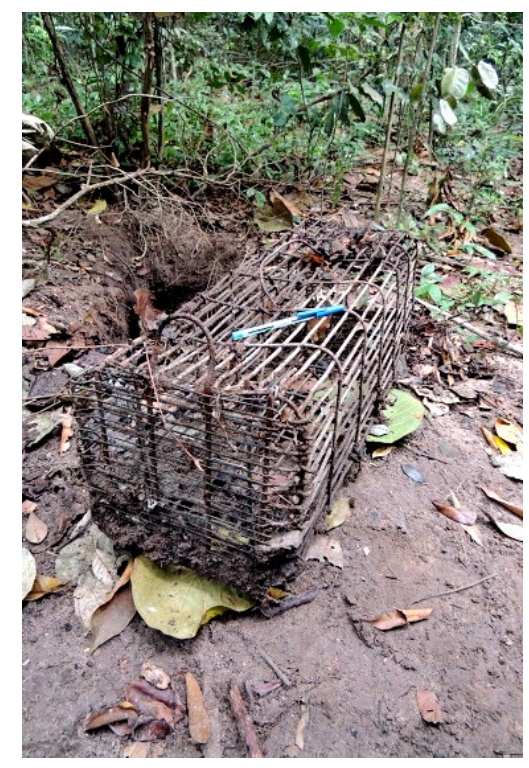

b

Figura 17. Caça de "espera" (a) e armadilha tipo "ratoeira" (b), na RVS Mata do Buraquinho, 27/01/2018, 29/10/2017. Fotos: Cláudio Almeida.
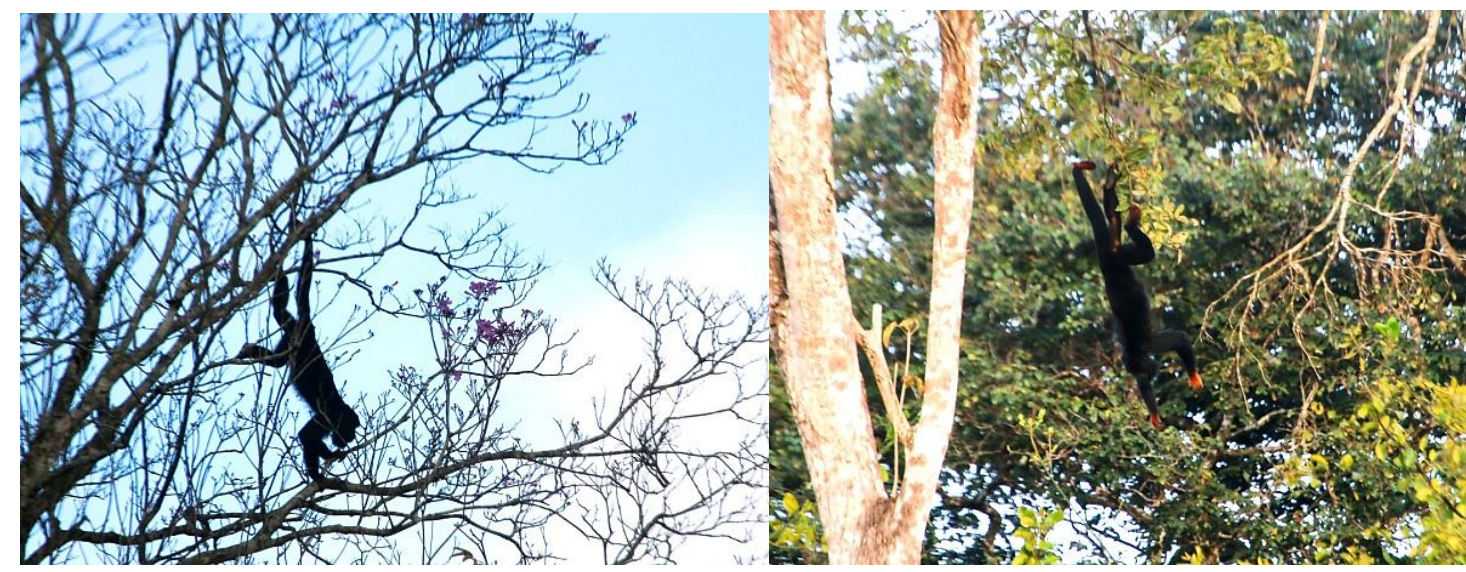

a

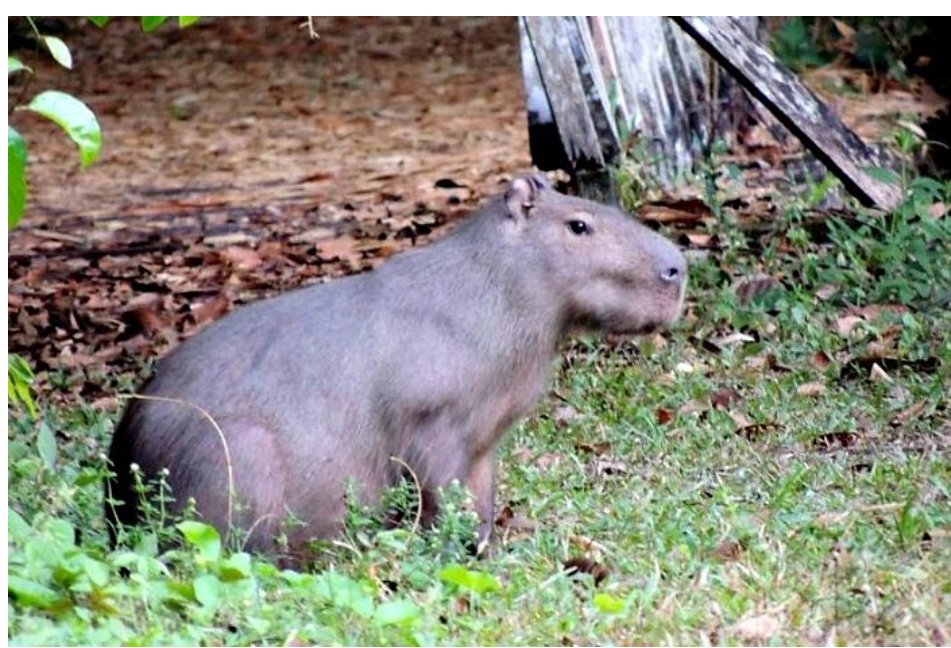

b

Figura 18. Guariba adulto (Alouatta belzebul), na borda da mata (a), fotos Bruno Veras; capivara (Hydrochoerus hydrochaeris), na margem do Rio Jaguaribe (b), foto Cláudio Almeida, na RVS Mata do Buraquinho, 25/10/2020, 31/12/2017.

Rev. Bras. Gest. Amb. Sustent., 2021, vol. 8, n. 18, p. 37-75. 


\section{Conclusões}

1. A composição da comunidade das 113 espécies de aves está representada por muitas espécies dependentes de florestas, sendo bem representada por passeriformes, particularmente pelas famílias de hábitos insetívoros e/ou frugívoros, tais como Tyrannidae, Thraupidae, Thamnophildae e Rhynchocyclidae, cerca de 35\% das espécies da avifauna da unidade de conservação, o que aponta para possibilidades de plano de recuperação e restauração ambiental na unidade de conservação e corredores ecológicos, incluindo estratégias específicas que beneficiem esses grupos de aves que desempenham papel relevante nos processos ecológicos na restauração ambiental;

2. A comunidade de aves apresenta uma composição e riqueza de espécies similares a outros estudos realizados em diferentes remanescentes florestais de tamanhos variáveis, na Mata Atlântica da Região Nordeste do Brasil, utilizando metodologias similares ou especificamente as Listas de Mackinnon;

3. Como a RVS Mata do Buraquinho está inserida em uma área urbanizada, constatou-se que aproximadamente $25 \%$ das espécies são bioindicadoras de alterações de habitat, incluindo as aves consideradas urbanas ou de comportamento sinatrópico;

4. A RVS Mata do Buraquinho consiste em uma Unidade de Conservação de extrema relevância ecológica para a conservação da avifauna remanescente da Mata Atlântica; a qual congrega espécies endêmicas ameaçadas de extinção, além de espécies polinizadoras e dispersoras de sementes, que atuam ativamente como agentes de recuperação ambiental e manutenção dos processos ecológicos;

5. Foram registrados oito táxons endêmicos do Brasil e do Bioma Mata Atlântica, no Centro de Endemismo Pernambuco (CEP), cinco espécies e três subespécies. Destas, seis estão ameaçadas em diferentes categorias, como quatro vulneráveis, uma ameaçada e uma criticamente ameaçada, foram elas: Touit surdus, Xiphorhynchus atlanticus, Xenops minutus alagoanus, Hemitriccus griseipectus naumburgae, Leptodon forbesi, Iodopleura pipra leucopygia, respectivamente;

6. Os táxons ameaçados são dependentes de floresta e apresentam média $(n=4)$ a alta $(n=2)$ sensibilidade aos distúrbios ambientais provocados pelas ações antrópicas, tais como desmatamento e perda de habitat.

7. 0 táxon Iodopleura pipra leucopygia, criticamente ameaçado, provavelmente demonstra ser muito apto a manejo, pois se utiliza da própria arborização urbana do entorno da unidade de conservação como fonte de alimentação;

8. Apesar de considerado, tentativamente, com média sensibilidade às alterações de habitat, Hemitriccus griseipectus naumburgae, pode ser indicado com um táxon bioindicador em estudos específicos de alterações do ecossistema provocadas pelas mudanças climáticas antropogênicas;

9. Considerando a observação da literatura especializada, torna-se pertinente apontar que para táxons registrados na unidade de conservação, tratados como subespécies (Xenops minutus alagoanus, Iodopleura pipra leucopygiae e Hemitriccus griseipectus naumburgae), afins com táxons da Mata Atlântica e Amazônia, refletem os estudos taxonômicos desiguais para essas aves com essa classificação, os quais podem comprometer medidas efetivas locais para a conservação, tendo em vista a baixa resolutividade taxonômica para esses táxons ameaçados. 0 conservacionismo, a priori, precisa de unidades fixas para poder operar e as espécies - dependendo do conceito adotado - podem surgir e desaparecer com uma notável rapidez (Teixeira, D. M. com. pess.);

10. Dentre as espécies ameaçadas registradas na RVS Mata do Buraquinho, cabe destacar que o Psittacidae, apuim-de-cauda-amarela (Touit surdus), satisfaria alguns dos critérios (e.g. carisma e estado de conservação) utilizados para estabelecer uma espécie-bandeira ("flagship species"); a qual seria utilizada no sentido de sensibilizar a sociedade para a causa da conservação, na educação ambiental e garantir recursos financeiros para a gestão da unidade de conservação; 
11. Será necessária a criação de corredores ecológicos em propriedades privadas e públicas municipais, através da malha hídrica e da mata ciliar (APP's) remanescente do Rio Jaguaribe; na tentativa de expandir a área efetiva dos 512,93 ha da unidade de conservação, no sentido de garantir fluxo gênico a médio e longo prazo e a persistência das espécies ameaçadas de extinção dependentes de florestas. Cabe ressaltar que a RVS Mata do Buraquinho encontra-se isolada em uma complexa malha urbana, sem conectividade entre outros fragmentos florestais representativos, mas apresenta potencialidade funcional como núcleo dispersor de biodiversidade para a restauração ambiental ou recolonização. Para cumprir esse fim, torna-se necessário o incentivo ao desenvolvimento de pesquisas científicas na unidade de conservação e no seu entorno imediato;

12. Os impactos ambientais negativos constatados que afetam diretamente ou indiretamente a avifauna da RVS Mata do Buraquinho, tais como coleta e corte seletivo de plantas, poluição hídrica, pesca, caça (em "espera" e com armadilha "ratoeira"), queimadas, poluição sonora e (re)introdução de espécies da fauna nativa, alguns desses impactos provavelmente se dão porausência e/ou ineficiência de fiscalização efetiva naUC e outros por ausência de plano de manejo da unidade de conservação, um instrumento fundamental, a qual ainda não dispõe de tal instrumento de gestão. Entretanto, a implementação da educação ambiental que envolva as comunidades do entorno da unidade de conservação representa um instrumento de inclusão social de extrema relevância para a conservação dessa área protegida;

13. A RVS tem forte aptidão para a observação de aves, a qual pode ser incrementada tanto para os observadores experientes, numa pespectiva da "ciência cidadã", bem como incentivada nas atividades de educação ambiental com atividaes de extensão para escolas públicas e particulares, moradores do entorno e visitantes;

14. A RVS Mata do Buraquinho reúne alguns dos critérios que extrapolam a sua categoria como unidade de conservação; quando se tem não somente uma área em bom estado de conservação, riqueza em biodiversidade, espécies ameaçadas de extinção, bem como espécies endêmicas, criticamente ameaçadas de extinção e área com grande potencial para realização de pesquisas científicas.

\section{Agradecimentos}

Aos professores e amigos Dra. Maria Cristina Basílio Crispim da Silva e Dr. Gil Dutra Furtado, pelo apoio solidário e pelas valiosas sugestões para o bom andamento do projeto de pesquisa submetido à seleção no Programa de Pós-Graduação em Desenvolvimento e Meio em Ambiente (PRODEMA/Campus I - UFPB), no ano de 2016. Aos Sercretários de Meio Ambiente de João Pessoa Abelardo Jurema Neto e Djalma Pereira de Castro Filho pelo apoio e incentivo ao desenvolvimento do projeto. À Superintendência de Administração do Meio Ambiente (SUDEMA) e à direção do Jardim Botânico de João Pessoa pela autorização para realização da pesquisa na unidade de conservação Refúgio de Vida Silvestre Mata do Buraquinho (Autorização no 003/2017/JBBM/SUDEMA). Ao amigo biólogo Ronilson José da Paz, pelo incentivo e grande contribuição para a conclusão deste artigo. A Arinaldo Inácio das Neves, pela a elaboração dos mapas. Ao amigo Marco Antônio Freitas, Betejane de Oliveira e Hermínio Vilela pelas informações sobre o comércio ilegal de aves em Alagoas e Sergipe. Ao amigo professor Dr. Dante Martins Teixeira (MN/UFRJ) por continuar dando apoio e esclarencedo dúvidas fundamentais para a elaboração deste artigo, além de toda a contribuição na minha formação como ornitólogo, durante estágio no Setor de Ornitologia do Museu Nacional/UFRJ. Aos amigos Edvaldo E. Nunes, Vicent K. Lo, Sérgio Fukusima, Bruno Veras pela cessão de uso das fotografias. A Glauco A. Pereira pela autorização de uso da ilustração de L. forbesi em voo. Ao amigo biólogo Caio Bezerra de Mattos Brito por ceder a foto de $X$. atlanticus utilizada para trabalhos de campo. A Simone Porfírio Souza pelas contribuições sobre a situação de

Rev. Bras. Gest. Amb. Sustent., 2021, vol. 8, n. 18, p. 37-75. 
Alouatta belzebul, junto ao Centro de Primatologia do Brasil (CPB). Ao amigo e ornitólogo Dr. Marcos Raposo (MN/UFRJ) pelo auxílio na análise de sonogramas.

Dedico este artigo à memória de meu pai, Pedro Freire de Almeida, pelas primeiras aulas de conservação e ornitologia da minha vida; e à memória das espécies de aves extintas na Região Nordeste do Brasil, o caburé-de-pernambuco (Glaucidium mooreorum), o gritador-do-nordeste (Cichlocolaptes mazarbarnetti) e o limpa-folha-do-nordeste (Philydor novaesi).

\section{Conflito de interesses}

O autor declara não haver conflito de interesses.

\section{Referências}

Albuquerque, J. V.; Duré, R. C. O Rio Jaguaribe no Jardim Botânico Benjamim Maranhão, João Pessoa-PB. Perspectivas de medidas para mudança. Anais do Congresso Brasileiro de Gestão Ambiental e Sustentabilidade - Congestas 2013, v. 1, p. 301-305, 2013. Disponível em: <http://eventos.ecogestaobrasil.net/congestas2013/trabalhos/pdf/congestas2013et-05-029.pdf>. Acesso em: 23 out. 2019.

Almeida, A. C. [WA2540793, Dendroplex picus (Gmelin, 1788)]. Wiki Aves - A Enciclopédia das Aves do Brasil. 2014a. Disponível em: <http://www.wikiaves.com/2540793>. Acesso em: 13 set. 2020 .

Almeida, A. C. [WA2540817, Dendroplex picus (Gmelin, 1788)]. Wiki Aves - A Enciclopédia das Aves do Brasil. 2014b. Disponível em: <http://www.wikiaves.com/2540817>. Acesso em: 13 set. 2020.

Almeida, A. C. [WA2540822, Dendroplex picus (Gmelin, 1788)]. Wiki Aves - A Enciclopédia das Aves do Brasil. 2014c. Disponível em: <http://www.wikiaves.com/2540822>. Acesso em: 13 set. 2020 .

Almeida, A. C. [WA2423050, Iodopleura pipra (Lesson, 1831)]. Wiki Aves - A Enciclopédia das Aves do Brasil. 2016a. Disponível em: <http://www.wikiaves.com/2423050>. Acesso em: 15 nov. 2020.

Almeida, A. C. C. XC349078 - Xeno-canto. Sharing bird sounds from around the world. 2016b. Available from: <http://www.xeno-canto.org/349078>. Acesso em: 26 nov. 2020.

Almeida, A. C. [WA2646350,Touit surdus (Kuhl, 1820)]. Wiki Aves - A Enciclopédia das Aves do Brasil. 2017a. Disponível em: <http://www.wikiaves.com/2646350>. Acesso em: 07 set. 2020.

Almeida, A. C. [WA2646353, Touit surdus (Kuhl, 1820)]. Wiki Aves - A Enciclopédia das Aves do Brasil. 2017b. Disponível em: <http://www.wikiaves.com/2646353>. Acesso em: 07 set. 2020.

Almeida, A. C. [WA2646354, Touit surdus (Kuhl, 1820)]. Wiki Aves - A Enciclopédia das Aves do Brasil. 2017c. Disponível em: <http://www.wikiaves.com/2646354>. Acesso em: 07 set. 2020.

Almeida, A. C. [WA2646355, Touit surdus (Kuhl, 1820)]. Wiki Aves - A Enciclopédia das Aves do Brasil. 2017d. Disponível em: <http://www.wikiaves.com/2646355>. Acesso em: 07 set. 2020.

Almeida, A. C. [WA2763754, Xiphorhynchus atlanticus (Cory, 1916)]. Wiki Aves - A Enciclopédia das Aves do Brasil. 2017e. Disponível em: <http://www.wikiaves.com/ 2763754>. Acesso em: 12 set. 2020. 
Almeida, A. C. [WA2763758, Xiphorhynchus atlanticus (Cory, 1916)]. Wiki Aves - A Enciclopédia das Aves do Brasil. 2017f. Disponível em: <http://www.wikiaves.com/ 2763758>. Acesso em: 12 set. 2020.

Almeida, A. C. [WA3973109, Xiphorhynchus atlanticus (Cory, 1916)]. Wiki Aves - A Enciclopédia das Aves do Brasil. 2017g. Disponível em: <http://www.wikiaves.com/ 3973109>. Acesso em: 15 set. 2020.

Almeida, A. C. C. XC350747 - Xeno-canto. Sharing bird sounds from around the world. 2017h. Disponível em: <http://www.xeno-canto.org/350747>. Acesso em: 26 nov. 2020.

Almeida, A. C. [WA2435202, Iodopleura pipra (Lesson, 1831)]. Wiki Aves - A Enciclopédia das Aves do Brasil. 2017i. Disponível em: <http://www.wikiaves.com/2435202>. Acesso em: 15 nov. 2020.

Almeida, A. C. [WA2718106, Hemitriccus griseipectus (Snethlage, 1907)]. Wiki Aves - A Enciclopédia das Aves do Brasil. 2017j. Disponível em: <http://www.wikiaves.com/ 2718106>. Acesso em: 23 dez. 2020.

Almeida, A. C. [WA2718109, Hemitriccus griseipectus (Snethlage, 1907)]. Wiki Aves - A Enciclopédia das Aves do Brasil. 2017k. Disponível em: <http://www.wikiaves.com/ 2718109>. Acesso em: 23 dez. 2020.

Almeida, A. C. [WA2727902, Hemitriccus griseipectus (Snethlage, 1907)]. Wiki Aves - A Enciclopédia das Aves do Brasil. 2017l. Disponível em: <http://www.wikiaves.com/ 2727902 >. Acesso em: 23 dez. 2020.

Almeida, A. C. [WA2727938, Hemitriccus griseipectus (Snethlage, 1907)]. Wiki Aves - A Enciclopédia das Aves do Brasil. 2017m. Disponível em: <http://www.wikiaves.com/ 2727938>. Acesso em: 23 dez. 2020.

Almeida, A. C. [WA2833399, Hemitriccus griseipectus (Snethlage, 1907)]. Wiki Aves - A Enciclopédia das Aves do Brasil. 2017n. Disponível em: <http://www.wikiaves.com/ 2833399>. Acesso em: 23 dez. 2020.

Almeida, A. C. [WA2680378, Trogon curucui Linnaeus, 1766]. Wiki Aves - A Enciclopédia das Aves do Brasil. 2017o. Disponível em: <http://www.wikiaves.com/2680378>. Acesso em: 30 dez. 2020.

Almeida, A. C. [WA2697994, Manacus manacus (Linnaeus, 1766)]. Wiki Aves - A Enciclopédia das Aves do Brasil. 2017p. Disponível em: <http://www.wikiaves.com/ 2697994>. Acesso em: 30 dez. 2020.

Almeida, A. C. [WA2701814, Poecilotriccus fumifrons (Hartlaub, 1853)]. Wiki Aves - A Enciclopédia das Aves do Brasil. 2017q. Disponível em: <http://www.wikiaves.com/ 2701814 >. Acesso em: 30 dez. 2020.

Almeida, A. C. [WA2727853, Myiothlypis flaveola Baird, 1865]. Wiki Aves - A Enciclopédia das Aves do Brasil. 2017r. Disponível em: <http://www.wikiaves.com/2727853>. Acesso em: 30 dez. 2020.

Almeida, A. C. [WA2866183, Xenops minutus (Sparrman, 1788)]. Wiki Aves - A Enciclopédia das Aves do Brasil. 2018a. Disponível em: <http://www.wikiaves.com/ 2866183>. Acesso em: 25 out. 2020.

Almeida, A. C. [WA2871594, Xenops minutus (Sparrman, 1788)]. Wiki Aves - A Enciclopédia das Aves do Brasil. 2018b. Disponível em: <http://www.wikiaves.com/ 2871594>. Acesso em: 25 out. 2020.

Almeida, A. C. [WA2871601, Xenops minutus (Sparrman, 1788)]. Wiki Aves - A Enciclopédia das Aves do Brasil. 2018c. Disponível em: <http://www.wikiaves.com/ 2871601>. Acesso em: 25 out. 2020. 
Almeida, A. C. [WA2867591, Iodopleura pipra (Lesson, 1831)]. Wiki Aves - A Enciclopédia das Aves do Brasil. 2018d. Disponível em: <http://www.wikiaves.com/2867591>. Acesso em: 15 nov. 2020.

Almeida, A. C. C. XC401291 - Xeno-canto. Sharing bird sounds from around the world. 2018e. Available from: <http://www.xeno-canto.org/401291>. Acesso em: 26 nov. 2020.

Almeida, A. C. C.; Teixeira, D. M. Aves da Reserva Biológicas Guaribas, Mamanguape, Paraíba, Brasil. Revista Nordestina de Biologia, v. 19, n. 2, p. 3-14, 2010.

Almeida, S. M.; Franchin, A. G.; Marçal-Júnior, O. Estudo etnoornitológico no distrito rural de Florestina, Município de Araguari, Região do Triângulo Mineiro, Minas Gerais. Sitientibus, Série Ciências Biológicas, v. 6, p.26-36, 2006. Disponível em: <http://www.lorb.ib.ufu.br/artigos/etnoornitoflorentina.pdf>. Acesso em: 23 out. 2019.

Alves, R. N.; Policarpo, I. S.; Barboza, R. R. D.; Araújo, H. F. P. Perception and use of biodiversity in the vicinity of an urban conservation area, North Eastern Brazil. Indian Journal of Traditional Knowledge, v. 16, n. 1, p. 44-50, 2017. Disponível em: <http://nopr.niscair.res.in/bitstream/123456789/37012/1/IJTK 16(1) 44-50.pdf>. Acesso em: 23 out. 2019.

Andrade-Lima, D.; Rocha, M. G. Observações preliminares sobre a Mata do Buraquinho, João Pessoa, Paraíba. Anais do Instituto de Ciências Biológicas da Universidade Federal Rural de Pernambuco, v. 1, n. 1, p. 47-61, 1971.

Argel-de-Oliveira, M. M. Subsídios para a atuação de biólogos em Educação Ambiental. 0 uso de aves urbanas em educação ambiental. Mundo da Saúde, v. 20, n. 8, p. 263-270, 1996.

Barbosa, M. R. V. Estudo florístico e fitossociológico da Mata do Buraquinho, remanescente de Mata Atlântica em João Pessoa, Paraíba. Campinas: Universidade Estadual de Campinas, 1996. (Tese de doutorado).

Barnett, J. M.; Buzzetti, D. R. C. A new species of Cichlocolaptes Reichbach 1853 (Furnariidae), the 'gritador-do-nordeste', an undescribed trace of the fading bird life of Northeastern Brazil. Revista Brasileira de Ornitologia, v. 22, n. 2, p. 75-94, 2014. Disponível em: <http://www.revbrasilornitol.com.br/BJO/article/download/5702/ pdf_1>. Acesso em: 23 out. 2019.

Brasil. Decreto no 98.181, de 26 de setembro de 1989. Declara de preservação permanente a floresta e demais formas de vegetação da área que descreve. Disponível em: <http://www.planalto.gov.br/ccivil_03/decreto/1980-1989/D98181.htm>. Acesso em: 23 out. 2019.

Brasil. Instituto Chico Mendes de Conservação da Biodiversidade. Plano de Ação Nacional para a Conservação das Aves da Mata Atlântica. Brasília: MMA, 2018c. Disponível em: <https://www.icmbio.gov.br/portal/images/stories/docs-pan/pan-avesda-mata-atlantica/1-ciclo/pan-aves-da-mata-atlantica-sumario.pdf>. Acesso em: 22 out. 2020.

Brasil. Lei no 11.428, de 22 de dezembro de 2006. Dispõe sobre a utilização e proteção da vegetação nativa do Bioma Mata Atlântica, e dá outras providências. Disponível em: <http://www.planalto.gov.br/ccivil_03/_ato2004-2006/2006/lei/l11428.htm>. Acesso em: 23 out. 2019.

Brasil. Lei no 9.985, de 18 de julho de 2000. Regulamenta o art. 225, § 1ํ, incisos I, II, III e VII da Constituição Federal, institui o Sistema Nacional de Unidades de Conservação da Natureza e dá outras providências. Disponível em: <http://www.planalto.gov.br/ ccivil_03/leis/L9985.htm>. Acesso em: 23 out. 2019. 
Brasil. Livro Vermelho da Fauna Brasileira Ameaçada de Extinção. Volume I. 1. ed. Brasília: ICMBio/MMA, 2018a. Disponível em: <https://www.icmbio.gov.br/ portal/images/stories/comunicacao/publicacoes/publicacoes-diversas/livro_vermelho_ 2018_vol1.pdf>. Acesso em: 22 jan. 2020.

Brasil. Livro Vermelho da Fauna Brasileira Ameaçada de Extinção. Volume III - Aves. 1. ed. Brasília: ICMBio/MMA, 2018b. Disponível em: <https://www.icmbio.gov.br/portal/ images/stories/comunicacao/publicacoes/publicacoes-diversas/livro_vermelho_2018_ vol3.pdf>. Acesso em: 22 jan. 2020.

Brasil. Ministério do Meio Ambiente. Áreas prioritárias para conservação, uso sustentável e repartição de benefícios da biodiversidade brasileira - atualização: Portaria MMA no 9, de 23 de janeiro de 2007. Brasília: MMA, 2007a. Brasília: MMA, 2007. (Biodiversidade 31). Disponível em: <http://www.mma.gov.br/estruturas/chm/ _arquivos/biodiversidade31.pdf>. Acesso em: 23 out. 2019.

Brasil. Ministério do Meio Ambiente. Protoloco CEMAVE: Projeto de Monitoramento da Avifauna em Unidades de Conservação Federais do Bioma Caatinga. Cabedelo: MMA/CEMAVE, 2014a.

Brasil. Ministério do Meio Ambiente. Diversidade Biológica e Conservação da Floresta Atlântica ao Norte do Rio São Francisco. Brasília: MMA, 2005.

Brasil. Ministério do Meio Ambiente. Livro vermelho da fauna brasileira ameaçada de extinção. Brasília: MMA; Belo Horizonte: Fundação Biodiversitas, 2008. v. 2.

Brasil. Ministério do Meio Ambiente. Portaria MMA no 444, de 18 de dezembro de 2014b. Disponível em: <https://www.icmbio.gov.br/sisbio/images/stories/instrucoes_ normativas/PORTARIA_N\%C2\%BA_444_DE_17_DE_DEZEMBRO_DE_2014.pdf>. Acesso em: 23 out. 2019.

Brasil. Ministério do Meio Ambiente. Livro vermelho da fauna brasileira ameaçada de extinção. Brasília: ICMBio/MMA, 2016. (Sumário executivo).

Brasil. Projeto Radambrasil. Folha 24/25 Jaguaribe/Natal: geologia, geomorfologia, pedologia, vegetação, uso potencial da terra. Rio de Janeiro, 1981. (Levantamento de recursos naturais, 23).

Brasil. Resolução CONAMA no 357, de 17 de março de 2005. Dispõe sobre a classificação dos corpos de água e diretrizes ambientais para o seu enquadramento, bem como estabelece as condições e padrões de lançamento de efluentes, e dá outras providências. 2005. Available from: <http://www2.mma.gov.br/port/conama/legiabre. cfm?codlegi=459>. Acesso em: 30 dez. 2020.

Brasil. Resolução CONAMA no 391, de 25 de junho de 2007b. Define vegetação primária e secundária nos estágios inicial, médio e avançado de regeneração da Mata Atlântica no estado da Paraíba. Disponível em: <http://www2.mma.gov.br/port/conama/legiabre.cfm? codlegi $=536>$. Acesso em: 23 out. 2017.

Cabanne, G. S.; D’Horta, F. M.; Sari, E. H. R.; Santos, F. R.; Miyaki, C. Y. Nuclear and mitochondrial phylogeography of the Atlantic Forest endemic Xiphorhynchus fuscus (Aves: Dendrocolaptidae): Biogeography and systematics implications. Molecular Phylogenetics and Evolution, v. 49, p. 760-773, 2008.

Cabanne, G. S.; Trujillo-Arias N.; Calderon L.; D'Horta F. M.; Miyaki C. Y. Phenotypic evolution of an Atlantic Forest passerine (Xiphorhynchus fuscus): Biogeographic and systematic implications. Biological Journal of the Linnean Society, v. 113, p. 1047-1066, 2014.

Rev. Bras. Gest. Amb. Sustent., 2021, vol. 8, n. 18, p. 37-75. 
Callado, T. C. [WA4144628, Leptodon forbesi (Swann, 1922)]. Wiki Aves - A Enciclopédia das Aves do Brasil. 2021. Disponível em: <http://www.wikiaves.com/4144628>. Acesso em: 02 jan. 2021.

CBRO - Comitê Brasileiro de Registros Ornitológicos. Listas das aves do Brasil. Versão 22/03/2005. Disponível em: <http://www.museum.lsu.edu/ Remsen/SACC Baseline.html>. Acesso em: 23 out. 2019.

Cohn-Haft, M. A case study Amazonian biogeography: Vocal and DNA-sequence variation in Hemitriccus flycatcher. Baton Rouge, EUA: Louisiana State University, 2000. (Tese de doutorado).

Costa, R. G. A. Observação de aves como ferramenta didática para educação ambiental. Revista Didática Sistêmica, v. 6, p. 33-44, 2007.

Dekeyser, P. L. Une contribuition méconnue à l'ornithologie de l'état de la Paraíba (1). Revista Nordestina de Biologia, v. 2, n. 1/2, p. 127-145, 1979.

Dénes, F. V.; Silveira, L. S.; Seipke, S.; Thorstrom, R.; Clark, W. S.; Thiollay, J. The whitecollared kite (Leptodon forbesi Swann, 1922) and a review of the taxonomy of the greyheaded kite (Leptodon cayanensis Latham, 1790). The Wilson Journal of Ornithology, v. 123, n. 2, p. 323-331, 2011.

Dias, S. C.; Brescovit, A. D.; Couto, E. C. G.; Martins, C. F. Species richness and seasonality of spiders (Arachnida, Araneae) in an urban Atlantic Forest fragment in Northeastern Brazil. Urban Ecosystems, v. 9, n. 4, p. 323-335, 2006b. https://doi.org/10.1007/s11252-006$0002-7$

Dias, S. C.; Candido, D. M.; Brescovit, A. D. Scorpions from Mata do Buraquinho, João Pessoa, Paraíba, Brazil, with ecological notes on a population of Ananteris mauryi Lourenço (Scorpiones, Buthidae). Revista Brasileira de Zoologia, v. 23, n. 3, p. 707-710, 2006a. https://doi.org/10.1590/S0101-81752006000300014

Dunning, J. S. South American birds: An photographic aid to identification. Pennsylania: Harrowood Books, 1987.

Enedino, T. R.; Loures-Ribeiro, A.; Santos, B. A. Protecting biodiversity in urbanizing regions: The role of urban reserves for the conservation of Brazilian Atlantic Forest birds.

Perspective in Ecology and Conservation, v. 16, n. 1, p. 17-23, 2018. https://doi.org/10.1016/j.pecon.2017.11.001

Falcão, A. H.; Almeida, A. C. C.; Ramalho, A. P. Q.; Imperiano, B. O.; Lima, E. R. V.; Melo, G. N.; Araújo, G. C.; Gomes, H. M.; Pedrosa, I. L.; Kesselring, J.; Coelho, J. C. P.; Rodrugues Filho, J.; Andrade, L. A.; Falcone, N.; Duarte, P. F. L.; Bezerra, R.; Araújo, S. M.; Mendonça, S. R.; Accioly, S.; Pinto, V. G. Situação ambiental. In: Kohler, M. C. M. (Org.). Paraíba 92: perfil ambiental e estratégias. João Pessoa: SUDEMA/ABEMA, 1992.

Fialho M. S.; Valença-Montenegro M. M.; Silva, T. C. F.; Ferreira, J. G.; Laroque, P. 0. Ocorrência de Sapajus flavius e Alouatta belzebul no Centro de Endemismo Pernambuco. Neotropical Primates, v. 21, n. 2, 214-218, 2014. https://doi.org/10.1896/044.021.0215

Fukusima, S. [WA3652503, Iodopleura pipra (Lesson, 1831)]. Wiki Aves - A Enciclopédia das Aves do Brasil. 2019. Disponível em: <http://www.wikiaves.com/3652503>. Acesso em: 24 nov. 2020.

Furrier, M. Caracterização geomorfológica e do meio físico da Folha João Pessoa 1:100.000. São Paulo: Universidade de São Paulo, 2007. (Tese de doutorado).

Gadelha Neto, P. C. Trilhas ambientais do Jardim Botânico de João Pessoa. In: Paz, R. J.; Farias, T. (Orgs.). Gestão de áreas protegidas: processos e casos particulares. João Pessoa: Editora Universitária/UFPB, 2008. p. 271-286. 
Grantsau, R. K. H. Guia completo para identificação das aves do Brasil. São Carlos: Verde Vento, 2010. v. 2.

Herzog, S. K.; Kessler, M.; Cahill, T. M. Estimating species richness of tropical bird communities form rapid assessment data. The Auk, v. 119, p. 749-769, 2002. Disponível em: <http://www.faunaparaguay.com/Auk 119-3-749.pdf>. Acesso em: 23 out. 2019.

Hidvegi, F.; Delchambre, P. Enregistrer des chants d'oiseaux avec un smartphone. Version 1.0. May 2013. Disponível em: <http://www.xeno-canto.org/article/152>. Acesso em: 23 out. 2019.

Hume, J. P. Extinct birds. New York: Bloomsbury Publishing, 2017.

Huntington, H. P. Using traditional ecological knowledge in Science: Methods and

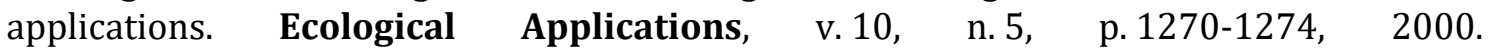
https://doi.org/10.1890/1051-0761(2000)010[1270:UTEKIS]2.0.CO;2

IBAMA - Instituto Brasileiro do Meio Ambiente e dos Recursos Naturais Renováveis. Projeto Alexandre Souto: integração das populações do entorno ao Jardim Botânico de João Pessoa-PB (uma proposta voltada para o ecoturismo, saúde, emprego, renda, educação, lazer e cultura). João Pessoa: IBAMA, Associação SOS Verde, CETEP, 1997.

IUCN - International Union for Conservation of Nature. The IUCN Red List of Threatened Species. Version 2020.2. Disponível em: <https://www.iucnredlist.org/>. Acesso em: 09 set. 2020.

Jorge Pádua, M. T. J. Sistema Brasileiro de Unidades de Conservação: de onde viemos e para onde vamos? Anais do Congresso Brasileiro de Unidades de Conservação, Curitiba, v. 1, p. 214-236, 1997.

Kesselring, J.; Ebert, H. Relação das borboletas encontradas na "Mata do Buraquinho", João Pessoa, Estado da Paraíba, Brasil. Revista Nordestina de Biologia, v. 2, n. 1/2, p. 105-118, 1979.

Lees, A. C. [WA488482, Leptodon forbesi (Swann, 1922)]. Wiki Aves - A Enciclopédia das Aves do Brasil. 2011. Disponível em: <http://www.wikiaves.com/488482>. Acesso em: 21 ago. 2020.

Levey, D. J.; Bolker, B. M.; Tewksbury, J. J.; Sargent, S.; Haddad, N. M. Effects of landscape corridors on seed dispersal by birds. Science, v. 309, n. 5731, p. 146-148, 2005. https://doi.org/10.1126/science.1111479

Lima, D. M. [WA1401095, Leptodon forbesi (Swann, 1922)]. Wiki Aves - A Enciclopédia das Aves do Brasil. 2014. Disponível em: <http://www.wikiaves.com/1401095>. Acesso em: 21 ago. 2020.

Lo, V. K. [WA1154578, Leptodon forbesi (Swann, 1922)]. Wiki Aves - A Enciclopédia das Aves do Brasil. 2013. Disponível em: <http://www.wikiaves.com/1154578>. Acesso em: 21 ago. 2020.

Mackinnon, J. Field guide to the birds of Java and Bali. Bulaksumur: Gadjah Mada University Press, 1991.

Mackinnon, J.; Phillipps, K. A field guide to the birds of Borneo, Sumatra, Java and Bali. Oxford: Oxford University Press, 1993.

Magalhães V. S.; Azevedo Júnior, S. M.; Lyra-Neves, R. M.; Telino-Júnior, W. R.; Souza D. P. Biologia de aves capturadas em um fragmento de Mata Atlântica, Igarassu, Pernambuco, Brasil. Revista Brasileira de Zoologia, v. 24, n. 4, p. 950-964, 2007. 
Marsden, S. J.; Whiffin, M.; Galetti, M.; Fielding, A. H. How well will Brazil's system of Atlantic Forest reserves maintain viable bird populations? Biodiversity and Conservation, v. 14, p. 2835-2853, 2005.

Mélo, B. P. M. Proposta de observação de aves como atividade estratégica à conservação ambiental no Jardim Botânico Benjamim Maranhão em João Pessoa-PB. João Pessoa: UFPB/PRODEMA, 2015. (Dissertação de mestrado).

Meyer de Schauensee, R. A guide to the birds of South American. Philadelphia: Academy of Natural Sciences of Philadelphia, 1970.

Minns, J.; Buzzetti, D.; Albano, C.; Grosset, A.; Whittaker, A.; Parrini, R. Aves do Brasil, vozes e fotografias: Floresta Atlântica, Cerrado, Caatinga, Pantanal, Campos Sulinos e Costa. Versão 1.0 (DVD-ROM). Vinhedo: Avis Brasilis, 2010. v. 1.

Niemi, G. J.; McDonald, M. E. Application of ecological indicators. Application of Ecological Indicators, v. 35, n. 1, p. 89-111, 2004. https://doi.org/10.1146/annurev. ecolsys.35.112202.130132

Oliveira-Santos, L. G.; Fernandez, F. A. Pleistocene rewilding, frankenstein ecosystems, and an alternative conservation agenda. Conservation Biology, v. 24, p. 4-5, 2010. https://doi.org/10.1111/j.1523-1739.2009.01379.x

Oren, D. C. Biogeografia e conservação de aves na Região Amazônica. In: Capobianco, J. P. R.; Veríssimo, A.; Moreira, A.; Sawyer, D.; Santos, I.; Pinto, L. P. (Eds.). Biodiversidade na Amazônia brasileira: avaliação e ações prioritárias para a conservação, uso sustentável e repartição de benefícios. São Paulo: Estação Liberdade e Instituto Socioambiental, 2001.

Pagano, I. S. A.; Sousa, A. E. B. A.; Wagner, P. G. C.; Ramos, R. T. C. Aves depositadas no Centro de Triagem de Animais Silvestres do IBAMA na Paraíba: uma amostra do tráfico de aves silvestres no estado. Ornithologia, v. 3, n. 2, p. 132-144, 2009.

Paraíba. Decreto no 21.264, de 28 de agosto de 2000. Cria o Jardim Botânico de João Pessoa, na Mata do Buraquinho e dá outras providências. Disponível em: <http://oads.org.br/leis/2558.pdf>. Acesso em: 23 out. 2019.

Paraíba. Decreto no 35.195, de 23 de julho de 2014. Cria o Refúgio de Vida Silvestre da Mata do Buraquinho, no Município de João Pessoa. Disponível em: <http://static.paraiba.pb.gov.br/2014/07/Diario-Oficial-24-07-2014.pdf>. Acesso em: 23 out. 2019.

Paraíba. Decreto no 36.955, de 10 de outubro de 2016. Define os limites do Refúgio de Vida Silvestre da Mata do Buraquinho, no Município de João Pessoa. Disponível em: <http://static.paraiba.pb.gov.br/2014/07/Diario-Oficial-24-07-2014.pdf>. Acesso em: 23 out. 2019.

Pereira, G. A. XC7540. Xeno-canto. Sharing bird sounds from around the world. 2006. Disponível em: <http://www.xeno-canto.org/7540>. Acesso em: 26 nov. 2020.

Pereira, G. A.; Dantas, S. M.; Periquito, M. C. Possível registro de Leptodon forbesi no Estado de Pernambuco. Revista Brasileira de Ornitologia, v. 14, n. 4, p. 441-444, 2006.

Pereira, G. A.; Dantas, S. M.; Silveira, L. F.; Roda, S. A.; Albano, C.; Sonntag, F. A.; Leal, S.; Periquito, M. C.; Malacco, G. B.; Lees, A. C. Status of the globally threatened forest birds of Northeast Brazil. Papéis Avulsos de Zoologia, v. 54, n. 14, p. 177-194, 2014. https://doi.org/10.1590/0031-1049.2014.54.14

Pereira, G. A.; Araújo, H. F. P.; Azevedo Júnior, S. M.; Angelieri, C. C.; Silveira, L. F. Distribution, threats and conservation of the white-collared kite Leptodon forbesi, Accipitridae), the most threatened raptor in the Neotropics. Papéis Avulsos de Zoologia, v. 59, p. 1-8, 2019. https://doi.org/10.11606/1807-0205/2019.59.28 
Pereira, G. A.; Araújo, H. F. P.; Azevedo Júnior, S. M. Distribution and conservation of three important bird groups of the Atlantic Forest in North-East Brazil. Brazilian Journal of Biology, v. 76, n. 4, p. 1004-1020. 2016. https://doi.org/10.1590/1519-6984.06815

Piacentini, V. Q.; Aleixo, A.; Agne, C. E.; Mauricio, G. N.; Pacheco, J. F.; Bravo, G. A.; Brito, G. R. R.; Naka, L. N.; Olmos, F.; Posso, S.; Silveira, L. F.; Betini, G. S.; Carrano, E.; Franz, I.; Lees, A. C.; Lima, L. M.; Pioli, D.; Schunck, F.; Amaral, F. R.; Bencke, G. A.; Cohn-Haft, M.; Figueiredo, L. F. A.; Straube, F. C.; Cesari, E. Annotated checklist of the birds of Brazil by the Brazilian Ornithological Records Committee. Revista Brasileira de Ornitologia, v. 23, n. 2, p. 91298, 2015. Disponível em: <http://www.cbro.org.br/Piacentini et al 2015 RBO.pdf>. Acesso em: 23 out. 2019.

Pinto, O. M. O. Novo catálogo das aves do Brasil. São Paulo: Revista dos Tribunais, 1978.

Pinto, O. M. O.; Camargo, E. A. Resultados ornitológicos de quatro recentes expedições do Departamento de Zoologia ao Nordeste do Brasil, com descrição de seis novas subespécies. Arq. Zool. S. Paulo, v. 11, p. 193-284, 1961.

Pinto, O. M. O. Resultados ornitológicos de duas viagens científicas ao Estado de Alagoas. Papéis Avulsos do Departamento de Zoologia, v. 12, n. 1, p. 1-98, 1954.

Piratelli, A.; Sousa, S. D.; Corrêa, J. S. Andrade, V. A.; Ribeiro, R. Y.; Avelar, L H.; Oliveira, E. F. Searching for bioindicators of forest fragmentation: Passerine birds in the Atlantic Forest of Southeastern Brazil. Brazilian Journal of Biology, v. 68, n. 2, p. 259-268, 2008. https://doi.org/10.1590/S1519-69842008000200006

Pires, M. G.; Silva Jr., N. J.; Feitosa, D. T.; Prudente, A. L. C.; Pereira Filho, G. A.; Zaher, H. A new species of triadal coral snake of the genus Micrurus Wagler, 1824 (Serpentes: Elapidae) from Northeastern Brazil. Zootaxa, v. 3811, n. 4, p. 569-584, 2014. https://doi.org/10.11646/zootaxa.3974.4.5

Pivatto, M. A. C.; Sabino, J. O turismo de observação de aves no Brasil: breve revisão bibliográfica e novas perspectivas. Atualidades Ornitológicas, n. 139, p. 12-13, 2007. Disponível em: <http://www.ao.com.br/download/A0139_10a13.pdf>. Acesso em: 23 out. 2019.

PMJP - Prefeitura Municipal de João Pessoa. Plano Municipal de Conservação e Recuperação da Mata Atlântica. João Pessoa: PMJP, Secretaria de Meio Ambiente, 2012.

Ribon, R. Amostragem de aves pelo método de lista de Mackinnon. In: Matter, S.; Straube, F. C.; Accordi, I. A.; Piacentini, V. Q.; Cândido-Jr., J. F. (Orgs.). Ornitologia e conservação: ciência aplicada, técnicas de pesquisa e levantamento. 1. ed. Rio de Janeiro: Technical Books, 2010. p. 33-44.

Ribon, R.; Marini, M. A. Small territory sizes and high densities of insectivorous birds in an Atlantic Forest secondary fragment, Brazil. Revista Brasileira de Ornitologia, v. 24, p. 303-313, 2016. Disponível em: <http://www.revbrasilornitol.com.br/BJO/article/ view/1352>. Acesso em: 09 set. 2020.

Roda, S. A.; Pereira, G. A.; Albano, C. Conservação de aves endêmicas e ameaçadas do Centro de Endemismo Pernambuco. Recife: Editora da UFPE, 2011.

Rodrigues, K. C. Padrão de atividades, comportamento alimentar, exploração de habitat e área de vida de um grupo de Sapajus flavius (Schreber, 1774) (Primates, Cebidae) em um fragmento de floresta atlântica, Paraíba, Brasil. Rio Tinto: Universidade Federal da Paraíba, 2013. (Dissertação de mestrado).

Rodrigues, K. C.; Delfim, F. R.; Castro, C. S. S.; França, F. G. R.; Leite Filho, E.; Mesquita, D. O.; Oliveira, F. A.; Santos, A. C. A.; Ferrari, S. F.; Valença-Montenegro, M. M. Strobilurus torquatus Wiegmann, 1834 (Squamata: Tropiduridae): New records from the Brazilian State of Paraíba and a geographic distribution map. Check List, v. 9, n. 3, p. 614-617, 2013.

Rev. Bras. Gest. Amb. Sustent., 2021, vol. 8, n. 18, p. 37-75. 
Disponível em: <http://www.checklist.org.br/getpdf?NGD232-12>. Acesso em: 23 out. 2019.

RPPN Estação Veracel. Plano de manejo. Eunápolis: Veracel Celulose, 2016. Available from: <https://www.icmbio.gov.br/portal/images/stories/plano-de-manejo/plano_de_ manejo_rppn_estacao_veracel.pdf $>$. Acesso em: 27 ago. 2020.

Ruiz-Esparza J.; Santos, C. S.; Cunha, M. A.; Ruiz-Esparza, D. P. B.; Rocha, P. A.; Beltrão-Mendes, R.; Ferrari, S. F. Diversity of birds in the Mata do Junco State Wildlife Refuge, a remnant of the Atlantic Forest of Northeastern Brazil. Check List, v. 11, n. 3, 1647, 2015. https://doi.org/10.15560/11.3.1647

Salvin, O. A list of the birds obtained by Mr. Henry Whitely in British Guiana. Ibis, v. 3, p. 291-306, 1885. https://doi.org/10.1111/j.1474-919X.1885.tb06246.x

Santana, G. G.; Vieira, W. L. S.; Pereira Filho, G. A.; Delfim, F. R.; Lima, Y. C. C.; Vieira, K. S. Herpetofauna em um fragmento de Floresta Atlântica no Estado da Paraíba, Região Nordeste do Brasil. Biotemas, v. 21, n. 1, p. 75-84, 2008. http://doi.org/10.5007/21757925.2008v21n1p75

Sick, H. Ornitologia brasileira. Rio de Janeiro: Nova Fronteira, 1997.

Sick, H. Ornitologia brasileira: uma introdução. Brasília: Editora da UnB, 1985. 2 v.

Sigrist, T. Guia de campo: avifauna brasileira. São Paulo: Avis Brasilis, 2014.

Silva, M. B.; Mamede, S. B. Grupos de observadores de aves e mamíferos como estratégia para a conservação da biodiversidade do cerrado. Anais do I Congresso Regional de Educação Ambiental para a Conservação do Cerrado, Quirinópolis, p. 55-58, 2005.

Simon, A.; Gouveia, M. T. J. 0 destino das espécies: como e por que estamos perdendo a biodiversidade. Rio de Janeiro: Garamond, 2011.

Snow, D. The cotingas: Bellbirds, umbrellabirds and their allies. London: British Museum (Natural History), Oxford: Oxford University Press, 1982.

Sousa, A. E. [WA1400575, Leptodon forbesi (Swann, 1922)]. Wiki Aves - A Enciclopédia das Aves do Brasil, 2014. Disponível em: <http://www.wikiaves.com/1400575>. Acesso em: 21 ago. 2020.

Souza, C.E. A. R. Exposição das espécies do gênero Hemitriccus (Aves, Rhynchocyclidae) a mudanças climáticas futuras. Rio de Janeiro: UNIRIO, 2017. (Dissertação de mestrado).

Souza, S. P. Ecologia e conservação de Alouatta belzebul belzebul (Primates, Atelidae) na Paraíba, Brasil. Belo Horizonte: Universidade Federal de Minas Gerais, 2005. (Tese de doutorado).

Stotz, D. F.; Fitzpatrick III, J. W.; Parker, T. A.; Moskovits, D. R. Neotropical birds ecology and conservation. Chicago: The University of Chicago Press, 1996.

SUDEMA - Superintendência de Administração do Meio Ambiente. Estudo para subsidiar a criação de unidade de conservação de proteção integral da Mata do Buraquinho Paraíba. João Pessoa: SUDEMA, 2014.

Teixeira, D. M.; Otoch, R.; Luigi, G.; Raposo, M. A.; Almeida, A. C. C. Notes on some birds of Northeastern Brazil (5). Bulletin of the British Ornithologists' Club, v. 113, n. 1, p. 48-52, 1993.

Teixeira, D. M.; Porto, M.; Lourine, M. L.; Person, V. G. Animais vertebrados ameaçados de extinção na Estação Veracruz. Eunápolis: Veracruz Florestal, 1995. 
Teixeira, D. M.; Nacinovic, J. B.; Pontual, B. Notes on some birds of Northeastern Brazil (2). Bulletin of the British Ornithologists' Club, v. 107, n. 4, p. 151-157, 1987.

Telino-Júnior, W. R.; Dias, M. M.; Azevedo Júnior, S. M.; Lyra-Neves, R. M.; Larrazábal M. E. L. Estrutura trófica da avifauna na Reserva Estadual de Gurjaú, Zona da Mata Sul, Pernambuco, Brasil. Revista Brasileira de Zoologia, v. 22, n. 4, p. 962-973, 2005. https://doi.org/10.1590/S0101-81752005000400024

Terborgh, J.; Robinson, S. K.; Parker III, T. A.; Munn, C. A.; Pierpont, N. Structure and organization of an Amazonian forest bird community. Ecological Monographs, v. 60, n. 2, p. 213-238, 1990. https://doi.org/10.2307/1943045

Thomas, W. W. The Atlantic Coastal Forest of Northeastern Brazil. 1. ed. New York: New York Botanical Garden Press, 2008. v. 1.

Vielliard, J. M.; Almeida, M. E.; Anjos, L.; Silva, W. R. Levantamento quantitativo por pontos de escuta e o Índice Pontual de Abundância (IPA). In: Matter, S.; Straube, F. C.; Accordi, I. A.; Piacentini, V. Q.; Cândido-Jr, J. F. (Orgs.). Ornitologia e conservação: ciência aplicada, técnicas de pesquisa e levantamento. 1. ed. Rio de Janeiro: Technical Books, p. 47-60, 2010.

Wikiaves. A Enciclopédia das Aves do Brasil. 2017. Disponível em: <http://www.wikiaves.com>. Acesso em: 23 out. 2017.

Wikiaves. A Enciclopédia das Aves do Brasil. 2020. Disponível em: $<$ http://www.wikiaves.com>. Acesso em: 06 dez. 2020.

Zenaide, H. Aves da Paraíba. João Pessoa: Teone, 1953.

Informação da Licença: Este é um artigo Open Access distribuído sob os termos da Licença Creative Commons Attribution, que permite uso irrestrito, distribuição e reprodução em qualquer meio, desde que a obra original seja devidamente citada. 